\title{
Optimization of organic Rankine cycle power systems considering multistage axial turbine design
}

Meroni, Andrea; Andreasen, Jesper Graa; Persico, Giacomo; Haglind, Fredrik

Published in:

Applied Energy

Link to article, DOI:

10.1016/j.apenergy.2017.09.068

Publication date:

2018

Document Version

Peer reviewed version

Link back to DTU Orbit

Citation $(A P A)$ :

Meroni, A., Andreasen, J. G., Persico, G., \& Haglind, F. (2018). Optimization of organic Rankine cycle power systems considering multistage axial turbine design. Applied Energy, 209, 339-354.

https://doi.org/10.1016/j.apenergy.2017.09.068

\section{General rights}

Copyright and moral rights for the publications made accessible in the public portal are retained by the authors and/or other copyright owners and it is a condition of accessing publications that users recognise and abide by the legal requirements associated with these rights.

- Users may download and print one copy of any publication from the public portal for the purpose of private study or research.

- You may not further distribute the material or use it for any profit-making activity or commercial gain

- You may freely distribute the URL identifying the publication in the public portal 


\title{
Optimization of organic Rankine cycle power systems considering multistage axial turbine design
}

\author{
Andrea Meroni ${ }^{\mathrm{a}, *}$, Jesper Graa Andreasen ${ }^{\mathrm{a}}$, Giacomo Persico ${ }^{\mathrm{b}}$, Fredrik Haglind ${ }^{\mathrm{a}}$ \\ ${ }^{a}$ Department of Mechanical Engineering, Technical University of Denmark, Nils Koppels Allé, Building \\ 403, 2800 Kongens Lyngby, Denmark; \\ ${ }^{b}$ Dipartimento di Energia, Politecnico di Milano, Via Lambruschini 4, 20156 Milano, Italy
}

\begin{abstract}
Organic Rankine cycle power systems represent a viable and efficient solution for the exploitation of medium-to-low temperature heat sources. Despite the large number of commissioned units, there is limited literature on the design and optimization of organic Rankine cycle power systems considering multistage turbine design. This work presents a preliminary design methodology and working fluid selection for organic Rankine cycle units featuring multistage axial turbines. The method is then applied to the case of waste heat recovery from a large marine diesel engine. A multistage axial turbine model is presented and validated with the best available data from literature. The methodology allows the identification of the most suitable working fluid considering the trade-off between cycle and multistage turbine designs. The results of the optimization of cycle and turbine suggest that the fluid n-butane yields the best compromise in terms of cycle net power output, turbine cost and efficiency for the considered case study. When a conservative design approach is adopted, the turbine features a two-stage configuration with supersonic converging nozzles and post-expansion. Conversely, a single-stage turbine featuring a supersonic converging-diverging nozzle and Mach number up to 2 is the resulting ideal choice when a more advanced design approach is implemented.
\end{abstract}

Keywords: organic Rankine cycle, axial turbine, multistage turbine, waste heat recovery, marine diesel engine, optimization

2010 MSC: 00-01, 99-00

\section{Introduction}

Organic Rankine cycle power systems are employed in a range of different fields such as biomass applications, geothermal heat recovery, industrial waste heat recovery and solar applications. Compared to gas and steam turbines, the relatively small enthalpy drop in the expansion is advantageous for the ORC turbine design since it allows

\footnotetext{
${ }^{*}$ Corresponding author

Email addresses: andmer@mek.dtu.dk (Andrea Meroni), jgan@mek.dtu.dk (Jesper Graa Andreasen), giacomo.persico@polimi.it (Giacomo Persico), frh@mek.dtu.dk (Fredrik Haglind)
} 
for the use of only one or a few turbine stages. For a given external heat source, the preliminary design of the ORC systems is performed by optimization of the thermodynamic cycle, which is typically hampered by technical and practical constraints. The system components such as the expander, heat exchangers and pump can be included in the cycle optimization or can be optimized in a subsequent stage of the design process.

Even though different aspects can be included in the preliminary design of ORC systems, a number of authors [1-4] have highlighted that the expander and working fluid are the two key elements.

Song et al. [5], Yun et al. [6], Yang and Yeh [7, 8] and Andreasen et al. [9] performed design and optimization of ORC systems for marine applications but neglected the details of the expander design. Toffolo et al. [10], Maraver et al. [11] and Vivian et al. [12] proposed different methodologies for selecting the optimal working fluid and cycle configuration in ORC systems; however, in all cases the isentropic turbine efficiency was set to a fixed value. Astolfi et al. [13] and Martelli et al. [14] performed detailed thermodynamic and techno-economic analyses on ORC systems including multistage turbine optimization for geothermal and biomass applications, respectively. The aforementioned authors designed the ORC system by means of an assumption of the turbine efficiency, or estimated the turbine performance by interpolation of a statistical correlation developed for single-stage machines. Da Lio et al. [15] tackled the issue by constructing performance maps for single-stage axial turbines including the critical temperature of the working fluid as an additional parameter. Recently, White and Sayma [16] proposed a coupled analysis and optimization process of a small-scale ORC and a single-stage radial turbine with the aim to improve the economy-of-scale of the system. The authors developed performance maps based on a modified similitude theory to predict the performance of the turbine and of the ORC system.

In previous publications the present authors $[17,18]$ developed a methodology for a coupled optimization of an organic Rankine cycle unit and an axial turbine, and demonstrated that it is essential to include the design of the turbine in order to make accurate estimations of the cycle performance. In Refs. [17, 18], a single-stage axial turbine model was validated and employed. However, multistage turbine solutions are more suitable for applications requiring large power output and high expansion ratio, since they ensure better efficiency and limit the turbine loading under these conditions [19]. Multistage axial turbine arrangements are used by many ORC manufacturers, as documented in Colonna et al. [20], and a number of exemplary turbines have been documented, see Table 1. However, the literature on their design and optimization procedures is very limited. Some authors [21-25] presented the main criteria used in the development of the turbines in Table 1, however without providing the full details of their design and optimization methods. Other authors [26-28] have focused only on the analysis of the flow and performance of multistage ORC turbines using CFD techniques for a given turbine geometry. In all previous references, i.e. Refs. [21-28], the multistage turbine design was decoupled from the optimization of the ORC system. To the best of our knowledge, the most advanced approach where the multistage turbine performance is included in the ORC system optimization, is that proposed recently by Macchi and Astolfi [19]. They constructed a-priori correlations to predict the turbine isentropic efficiency as a function of the size parameter and volume flow rate ratio for 
Table 1: Documented multistage ORC axial turbines.

\begin{tabular}{|c|c|c|c|c|c|c|c|c|c|}
\hline Author & Manufacturer & year field & $\begin{array}{l}\text { Power } \\
{[\mathrm{kW}]}\end{array}$ & $N_{s t}$ & $\begin{array}{l}\text { Pressure } \\
\text { ratio }\end{array}$ & $\mathrm{N}$ [rpm] & $\begin{array}{l}\mathrm{rm} \\
{[\mathrm{mm}]}\end{array}$ & fluid & Ref. \\
\hline Verneau & Bertin \& Cie & 1977 solar & 54 & 2 & 142 & 7700 & 145 & $F C-75$ & [24] \\
\hline Osnaghi et al. & Gemmindustria & 1979 solar & 8 & 2 & 120 & 24000 & 90 & $\mathrm{C}_{6} \mathrm{H}_{5} \mathrm{Cl}$ & [22] \\
\hline $\begin{array}{l}\text { Bado et al., } \\
\text { Angelino et } \\
\text { al., Barutti et } \\
\text { al. }\end{array}$ & Gemmindustria & $\begin{array}{l}\text { 1979-solar } \\
1983\end{array}$ & 35 & 4 & 116 & 6700 & 120 & $C_{8} F_{16}$ & $\begin{array}{l}{[21,} \\
29,30]\end{array}$ \\
\hline Verneau & Bertin \& Cie & 1980 WHR & 1350 & 2 & 100 & 14000 & 176 & Fluorinol 85 & [24] \\
\hline $\begin{array}{l}\text { Angelino et } \\
\text { al. }\end{array}$ & Turboden & 1984 WHR & 100 & 2 & 24.9 & 3030 & 430 & $\mathrm{C}_{6} \mathrm{H}_{4} \mathrm{Cl}_{2}$ & $\begin{array}{l}{[23,} \\
31]\end{array}$ \\
\hline $\begin{array}{l}\text { Angelino et } \\
\text { al. }\end{array}$ & Turboden & 1984 WHR & 100 & 2 & 13.64 & 3030 & 430 & $\mathrm{C}_{8} \mathrm{H}_{10}$ & [31] \\
\hline Jokinen et al. & $\mathrm{n} / \mathrm{a}$ & 1998 WHR & 25 & 2 & $>100$ & $\begin{array}{l}40000 \\
48000\end{array}$ & $\mathrm{n} / \mathrm{a}$ & toluene & [25] \\
\hline $\begin{array}{l}\text { Obernberger } \\
\text { and Hammer- } \\
\text { schmid }\end{array}$ & Turboden & 2001 Biomass & 400 & 2 & $\mathrm{n} / \mathrm{a}$ & $\mathrm{n} / \mathrm{a}$ & $\mathrm{n} / \mathrm{a}$ & silicon oil & {$[32]$} \\
\hline Nasir et al. & Ormat Inc. & 2003 WHR & 4500 & 2 & $\sim 30$ & 3600 & n.a. & n-pentane & [33] \\
\hline
\end{tabular}

a fixed number of stages (up to three). The formula was developed using a mean-line model [34] employing ideal gas assumptions and optimizing the rotational speed. By using the proposed correlations, the thermodynamic cycle can be optimized to assess the impact of the different number of stages on the system performance. The approach by Macchi and Astolfi [19] is very general; however, it does not provide a specific optimal design for the considered application, i.e. the rotational speed is always set to the optimal value, the fluid is considered as an ideal gas, and the number of stages is limited to three. Moreover, the approach follows the same design philosophy for single and multi-stage turbine configurations; whereas in real applications key decision criteria such as performance, cost, working fluid limitations and technical aspects may set additional constraints on the turbine design, leading to different solutions.

There are a few mean-line models for multistage ORC turbine design in use by companies and research institutes, including AXTUR [35], used in the aforementioned approach by Macchi and Astolfi [19], and zTurbo [36, 37]. These codes underwent intense development, and their reliability was successfully assessed by several companies [38]; however, their detailed validation has yet to be published in the scientific literature (even though, in the case of zTurbo, a partial validation was presented in Ref. [39]). For this reason, there is the need to publish validation details of multistage ORC turbine models in the open literature.

The objective of this paper is to extend the design methodology of ORC power systems by including the optimal preliminary design of the axial turbine in the most general multistage layout. To this end, the paper presents a comprehensive strategy for turbine model validation, cycle and turbine combined optimization, and analysis of the results. This work is limited to consider steady-state analyses at design conditions. A multistage turbine model is developed and validated with two well-documented test 
cases from the literature, one of which is an ORC turbine. The design methodology for cycle and turbine is presented, and two different turbine design approaches are proposed. Then, the methodology is applied to the case of waste heat recovery from a large marine diesel engine, in order to show how it can be used in a real application.

This paper introduces several novel elements: (i) it presents the detailed validation of a mean-line model of ORC multistage axial turbines; (ii) it considers two alternative turbine design approaches, which designers may adopt according to their key decision criteria; (iii) it proposes a methodology for combined optimization of an ORC system and an ORC multistage turbine, in which the turbine layout and performance become additional criteria for the working fluid selection in a specific application.

Compared to the method used by Macchi and Astolfi [19], the methodology presented here allows optimizing the cycle and turbine for a specific application and including real-gas models. Overall the results and the method provide a solid contribution to state-of-the-art, of relevance for researchers as well as engineers and decisionmakers.

The paper is structured as follows: Section 2 presents the case study, the methods for the cycle and turbine designs, the criteria for the working fluid selection, and the validation of the multistage turbine model. Section 3 presents the results of the turbine model validation and of the optimization with the ORC system. Section 4 discusses the results. Conclusions are drawn in Section 5.

\section{Methods}

Figure 1 illustrates a schematic of the workflow methodology adopted in this study. Two different turbine design approaches were adopted, namely conservative design and advanced design, which are explained in more detail in Sec. 2.4. Based on the inputs from the case study (Sec. 2.1), a working fluid preselection process was performed (Sec. 2.2). As a starting point, an isentropic turbine efficiency of 0.8 and a singlestage design were assumed. Then, cycle and turbine were optimized for each working fluid candidate following an iterative process described in Sec. 2.6. In the conservative design approach, the maximum Mach number in the optimized turbine solutions was checked for being within a predefined value to ensure a conservative turbine design (see Sec. 2.4). If the constraint was not satisfied, a new combined optimization step was performed using an additional turbine stage. Finally, a performance index was computed (Sec. 3.3), incorporating the effects of both turbine and cycle designs. This parameter was also used to select the minimum number of stages in the advanced design approach and to decide on the possible insertion of a gearbox. A number of fluid candidates having the highest performance index was selected. The selection of the most suitable working fluid is discussed (Sec. 4) based on technical and environmental aspects, and the requirements of the specific application. The aforementioned steps and the validation of the multistage turbine model are described hereafter.

\subsection{Case study and cycle modelling}

The selected case study is the waste heat recovery from the exhaust gases, jacket cooling water and scavenge air of a $37 \mathrm{MW}$ diesel engine aboard a container ship [40]. 


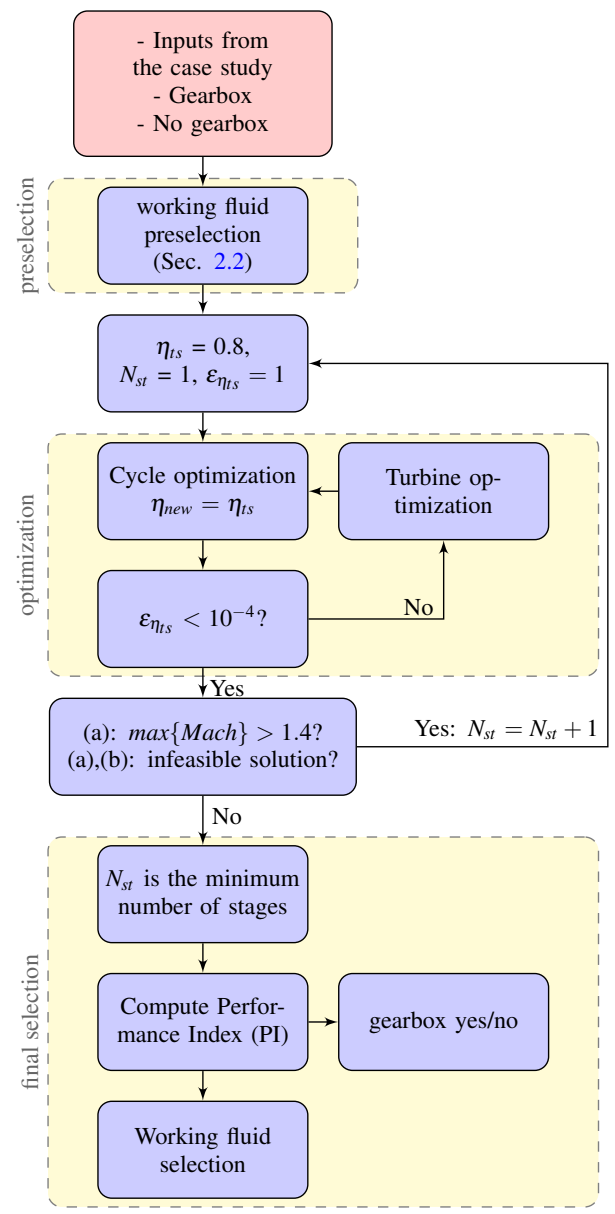

Figure 1: Flow chart of the adopted methodology for the cases with (a) conservative design and (b) advanced design.

The engine employs a heavy fuel oil with sulphur content, of about $3 \%$ and operates most of the time at low loads. In order to exploit fully the engine's waste heat, without oversizing the unit, we chose to design the ORC system at $75 \%$ engine load. Figure 2 shows a sketch of the ORC unit, and Table 2 lists the ORC modelling conditions. In addition to the exhaust gases, the jacket water and scavenge air were included as heat sources in order to obtain a higher system net power output from the ORC unit, and to preheat the working fluid at the pump outlet to the required level to avoid sulphuric acid condensation [41]. We found that a recuperator is not required. When the exhaust gases exit the engine, they are first used for generating service steam $(2 \mathrm{t} / \mathrm{h})$ for onboard heating purposes. After the service steam-boiler, the exhaust gases enter the ORC at $235.85^{\circ} \mathrm{C}$. The temperature of the working fluid at the boiler inlet was limited to $135^{\circ} \mathrm{C}$ to avoid sulphuric acid condensation [40]. The turbine can potentially be equipped with 


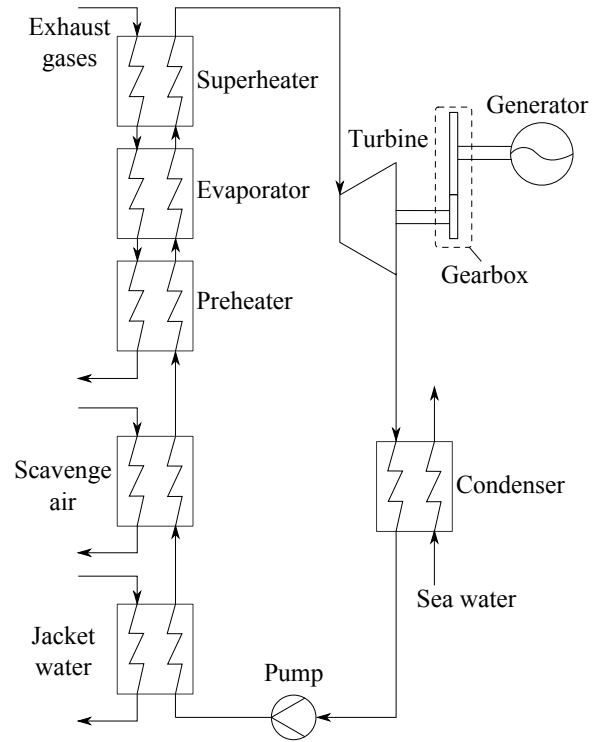

Figure 2: Organic Rankine cycle unit.

Table 2: Modelling conditions of the ORC unit.

\begin{tabular}{lrr}
\hline \hline Parameter & Value & Unit \\
\hline Exhaust gases & 235.85 & \\
Inlet temperature & 62.6 & $\mathrm{o}$ C \\
Mass flow & 1.1 & $\mathrm{~kJ} /(\mathrm{kg} \cdot \mathrm{K})$ \\
Heat capacity & & \\
Boiler & 20 & ${ }^{\circ} \mathrm{C}$ \\
Pinch point & 135 & ${ }^{\circ} \mathrm{C}$ \\
Minimum inlet temperature & & \\
Condenser & 30 & ${ }^{\circ} \mathrm{C}$ \\
Fluid condensation temperature & & \\
$\begin{array}{l}\text { Pump } \\
\text { Isentropic efficiency }\end{array}$ & 0.7 & - \\
Turbine & & \\
Isentropic efficiency (initial iteration) & 0.8 & - \\
Minimum outlet vapour quality & 1 & - \\
Gearbox efficiency & 0.97 & - \\
Generator efficiency & 0.95 & - \\
Jacket water & & \\
Available heat flow rate & 9230 & $\mathrm{~kW}$ \\
Fluid outlet temperature & 80 & ${ }^{\circ} \mathrm{C}$ \\
$\begin{array}{l}\text { Scavenge air } \\
\text { Inlet temperature } \\
\text { Available heat flow rate }\end{array}$ & & \\
\hline \hline
\end{tabular}

a gearbox, affecting both the system performance and turbine design. The suitability of the gearbox solution is discussed in Sec. 3. The heat exchangers in the cycle were modelled with a pinch point approach. 


\subsection{Preliminary working fluid selection}

In order to screen the suitability of the different working fluid candidates, some preselection criteria were used. Fluid candidates were selected according to indications in the literature [5, 42-45] for a waste heat recovery source of $235^{\circ} \mathrm{C}$, and according to their availability in commercial units $[20,43,46]$. The working fluids were discarded in the case they presented the following attributes: a thermal stability limit lower than the hot fluid inlet temperature, a critical temperature lower than the minimum admissible temperature at the boiler inlet, a non-zero ozone depleting potential (ODP) [47] or a global warming potential (GWP) $>150$ [48]. In the latter case, exception was made for those fluids currently used by manufacturers. Practical limitations on maximum and minimum pressures allowed in the ORC unit were also considered based on the indications by Rayegan et al. [49], Drescher and Brüggeman [50], and MAN Diesel $\&$ Turbo [40]. Finally, the work was limited to subcritical cycle operation, with a maximum limit of 0.8 in reduced pressure, in order to avoid excessive pressure in the boiler and problems during operating conditions close to the critical point. Table 3 shows the list of preselected working fluids.

Table 3: Preliminary screening of working fluid candidates.

\begin{tabular}{|c|c|c|c|c|c|c|c|c|}
\hline Fluid & $\begin{array}{l}T_{c} \\
{[\mathrm{~K}]} \\
\end{array}$ & $\begin{array}{l}\text { GWP } \\
{[-]} \\
\end{array}$ & $\begin{array}{l}\text { ODP } \\
{[-]} \\
\end{array}$ & tox./flamm. ${ }^{(*)}$ & $\begin{array}{l}\text { Thermal stability } \\
\text { limit } \\
{[\mathrm{K}]}\end{array}$ & $\begin{array}{l}\text { Condensation } \\
\text { pressure }^{(* *)} \\
{[\mathrm{bar}]}\end{array}$ & $\begin{array}{l}\text { Manufacturer } \\
{[-]}\end{array}$ & $\begin{array}{l}\text { Ref. } \\
{[-]}\end{array}$ \\
\hline n-pentane & 469.7 & $4 \pm 2$ & & $4 / 1$ & $573.15-588.15$ & 0.82 & $\begin{array}{l}\text { Ormat } \\
\text { Atlas Copco }\end{array}$ & [51-53] \\
\hline isopentane & 460.3 & $4 \pm 3$ & & $4 / 1$ & $500.15-588.15$ & 1.09 & $\begin{array}{l}\text { Ormat } \\
\text { Atlas Copco }\end{array}$ & [51-53] \\
\hline MM & 518.7 & $\sim 0$ & 0 & $3 / 0$ & 573.15 & 0.07 & Turboden & [54-56] \\
\hline n-hexane & 507.8 & $4-6$ & 0 & $3 / 1$ & n.a. & 0.25 & $\begin{array}{l}- \\
\text { Ormat } \\
\text { Turboden }\end{array}$ & \\
\hline cyclopentane & 511.7 & $<25$ & 0 & $3 / 1$ & $513.15-548.15$ & 0.51 & $\begin{array}{l}\text { GE Oil\& Gas } \\
\text { Atlas Copco } \\
\text { Aqylon }\end{array}$ & $\begin{array}{l}{[52,53,} \\
56-61]\end{array}$ \\
\hline benzene & 562.0 & 3.4 & 0 & $3 / 2$ & $>723.15$ & 0.16 & - & {$[51]$} \\
\hline cyclohexane & 553.6 & $4-6$ & 0 & $3 / 1$ & n.a. & 0.16 & - & \\
\hline toluene & 591.7 & 3.3 & 0 & $3 / 2$ & $>588.15$ & 0.0489 & $\begin{array}{l}\text { Tri-o-gen } \\
\text { Aqylon }\end{array}$ & $\begin{array}{l}{[51,57,} \\
61-64]\end{array}$ \\
\hline n-butane & 425.1 & 4 & 0 & $4 / 1$ & $563.15-693.15$ & 2.83 & $\begin{array}{l}\text { Atlas Copco } \\
\text { Ormat } \\
\text { Turboden }\end{array}$ & {$[52,53]$} \\
\hline $\mathrm{R} 245 \mathrm{fa}$ & 427.2 & 1030 & 0 & $0 / 2$ & $523.15-573.15$ & 1.78 & $\begin{array}{l}\text { GE-Energy } \\
\text { Calnetix } \\
\text { Cryostar } \\
\text { Atlas Copco }\end{array}$ & $\begin{array}{l}{[53,56,} \\
65-68]\end{array}$ \\
\hline ethanol & 514.71 & & 0 & $3 / 2$ & 550 & 0.10 & E-rational & \\
\hline
\end{tabular}

${ }^{(*)}=$ According to standard NPFA $704 .{ }^{(*)}$ at $30^{\circ} \mathrm{C}$. n.a. = datum not available. 


\subsection{Multistage axial turbine model}

TURAX is a mean-line model for the design and performance prediction of single and multistage axial turbines. In its present status the model is limited to steady-state analyses at design conditions. The model has been particularly conceived (i) to simulate axial-flow turbines operating with organic fluids and (ii) to perform a coupled optimization with the design of the ORC system. The details of the single-stage axial turbine model were presented in previous publications $[17,18]$. The main features of the multistage axial turbine model are described hereafter:

(1) TURAX performs the design of a multistage turbine by simultaneous optimization of each stage variable, in agreement with the indications by Persico and Pini [38] for ORC turbines. The decision variables of the multistage model are given in Table 4. The stage inlet axial velocity is specified only for the first stage, and the rotational speed is the same for all stages, since they are assumed to be mounted on the same shaft. In total 8 variables per stage are specified as input, in addition to rotational speed and stage inlet axial velocity.

(2) The pressure ratio of each stage is optimized based on the isentropic stage loading coefficient $\psi_{n}$. For a constant radius turbine design, the following relation holds:

$$
\Delta h_{0 s, t o t}=\frac{U_{m}^{2}}{2} \cdot \sum_{n=1}^{N_{s t}} \psi_{n}
$$

By means of Eq.1 it is possible to compute the mean peripheral speed $U_{m}$ and isentropic enthalpy drop $\Delta h_{0 s, t o t}$, thus also the total pressure ratio distribution across the stages.

(3) The flow angle and absolute velocity at the outlet of a stage were assumed to be the same as those at the inlet of the subsequent stage.

(4) The method by Craig and Cox [69] was employed, since it is the most comprehensive for the preliminary design of an ORC turbine. [23, 34, 35, 70]. The loss correlations used in the model were described in a previous work [17]. Supersonic converging nozzle blades are used for exit Mach numbers between 1 and 1.4, allowing a post-expansion downstream the blade opening. For higher Mach numbers, a supersonic adapted converging-diverging nozzle is used instead. In order to preserve the validity of the employed loss correlations and avoid high losses due to supersonic conditions, the rotor shape is converging with maximum relative Mach numbers at the rotor inlet and outlet of 0.8 and 1.4, respectively [71]. If the nozzle exit flow has a Mach number below 1.4, the throat is calculated as the minimum opening provided as input. Alternatively, it is calculated by a mass balance between the throat and the outlet of the nozzle, assuming a constant blade height in the divergent part. When an adapted converging-diverging nozzle was used, the blade profile design was assumed to be optimized, and the profile loss increment due to high Mach numbers is neglected as recommended in Dunham and Came [72].

\subsection{Selection of the number of stages}

The selection of the optimal number of stages may be based on a techno-economic analysis or on turbine aerodynamics and performance considerations. A number of 
Table 4: Decision variables of the multistage turbine model.

\begin{tabular}{|c|c|c|c|}
\hline Decision variable & Unit & Symbol & stage \\
\hline $\begin{array}{l}\text { 1) Isentropic stage loading co- } \\
\text { efficient }\end{array}$ & - & $\psi=\frac{2 \Delta h_{i s}}{U_{3 m}^{2}}$ & all \\
\hline 2) Nozzle minimum opening & $\mathrm{m}$ & $o_{\min }$ & all \\
\hline 3) Rotor opening & $\mathrm{m}$ & $o_{r}$ & all \\
\hline 4) Nozzle axial chord & $\mathrm{m}$ & $c_{n}$ & all \\
\hline 5) Rotor axial chord & $\mathrm{m}$ & $c_{r}$ & all \\
\hline $\begin{array}{l}\text { 6) Nozzle opening-to-pitch ra- } \\
\text { tio }\end{array}$ & - & $(o / s)_{n}$ & all \\
\hline 7) Rotor opening-to-pitch ratio & - & $(o / s)_{r}$ & all \\
\hline 8) Rotational speed & rpm & & first \\
\hline 9) Stage inlet axial velocity & $\mathrm{m} / \mathrm{s}$ & $C_{a 1}$ & first \\
\hline 10) Rotor flow coefficient & - & $\phi_{r}=\frac{C_{a 3}}{U_{3 m}}$ & all \\
\hline
\end{tabular}

different approaches to this topic can be found in Refs. [13, 14, 38, 73]. Nonetheless, an unequivocal method for the selection of the number of stages of ORC turbines has not been identified in the literature. This paper presents and compares two different approaches.

The first approach (denoted as conservative approach) follows a conservative turbine aerodynamic design, where the maximum Mach number in each stage is set to 1.4. This method allows avoiding excessive losses related to highly-supersonic flow conditions in the blade rows and the use of a simpler blade design (i.e. converging nozzle blades with post-expansion), and it can ensure higher reliability and performance at off-design conditions [21]. Moreover, it avoids using the conventional loss estimation procedures for highly supersonic flow conditions, for which not fully reliable correlations are available [74]. This method was adopted by previous authors $[36,75,76]$ in the design of ORC turbines.

A more compact solution would possibly employ converging-diverging nozzle blades with highly supersonic flows. For this reason, a second approach (denoted as advanced approach) is presented. In this case, the turbines have a higher stage loading and are designed with adapted converging-diverging nozzles. This approach was adopted by some other authors, see i.e. [24, 25], in the design of ORC turbines.

\subsection{Turbine model validation}

This multistage axial turbine model was validated using the design data of two reference turbines, having the most comprehensive and detailed information on experimental characterization and turbine geometry. The two test cases can be considered representative of the conservative and the advanced design approach, respectively. In addition, in the second test case, an uncertainty analysis was carried out in order to quantify the effects of the uncertainty in the assumed input parameters, on the results. The uncertainty analysis was applied only to the second test case, since the geometry of the first test case is well defined. 
Table 5: Decision and input variables of TURAX for the Hannover [77, 78] and Verneau $[24,85]$ turbines test cases.

\begin{tabular}{|c|c|c|c|c|c|c|c|c|c|c|c|c|c|}
\hline \multirow[b]{3}{*}{ Symbol } & \multirow{3}{*}{ Units } & \multicolumn{8}{|c|}{ Hannover turbine } & \multicolumn{4}{|c|}{ Verneau turbine } \\
\hline & & \multirow{2}{*}{\multicolumn{2}{|c|}{$\begin{array}{c}\text { Stage } 1 \\
\text { Nozzle Rotor }\end{array}$}} & \multirow{2}{*}{\multicolumn{2}{|c|}{$\begin{array}{c}\text { Stage } 2 \\
\text { Nozzle Rotor }\end{array}$}} & \multirow{2}{*}{\multicolumn{2}{|c|}{$\begin{array}{c}\text { Stage } 3 \\
\text { Nozzle Rotor }\end{array}$}} & \multirow{2}{*}{\multicolumn{2}{|c|}{$\begin{array}{c}\text { Stage } 4 \\
\text { Nozzle Rotor }\end{array}$}} & \multicolumn{2}{|c|}{ Stage 1} & \multicolumn{2}{|c|}{ Stage 2} \\
\hline & & & & & & & & & & Nozzle & Rotor & Nozzle & Rotor \\
\hline$\psi$ & - & & 2.61 & & .61 & 2. & 61 & 2. & 61 & 4.62 & & & 1.48 \\
\hline$o_{n, \min }, o_{r}$ & $\mathrm{~mm}$ & 12.24 & 13.52 & 13.01 & 13.65 & 13.84 & 13.79 & 14.78 & 13.94 & 1.00 & 3.50 & 1.52 & 2.03 \\
\hline$c_{n}, c_{r}$ & $\mathrm{~mm}$ & 44.80 & 39.10 & 44.30 & 38.50 & 45.50 & 37.50 & 46.50 & 37.50 & 20.00 & 28.00 & 37.00 & 37.00 \\
\hline$(o / s)_{n},(o / s)_{r}$ & & 0.332 & 0.393 & 0.342 & 0.383 & 0.353 & 0.372 & 0.365 & 0.360 & $0.276^{(* *)}$ & 0.467 & $0.500^{(* *}$ & $0.423^{(* *)}$ \\
\hline$N$ & $\mathrm{rpm}$ & \multirow{2}{*}{\multicolumn{6}{|c|}{$\begin{array}{c}7500 \\
57.8\end{array}$}} & & & \multicolumn{4}{|c|}{7700} \\
\hline$C_{a 1}$ & $\mathrm{~m} / \mathrm{s}$ & & & & & & & & & & & 1.23 & \\
\hline$\phi_{r}$ & - & \multicolumn{2}{|c|}{0.435} & \multicolumn{2}{|c|}{0.440} & \multicolumn{2}{|c|}{0.430} & \multicolumn{2}{|c|}{0.42} & \multicolumn{4}{|c|}{0.42} \\
\hline$\dot{m}$ & $\mathrm{~kg} / \mathrm{s}$ & \multicolumn{8}{|c|}{7.8} & \multicolumn{4}{|c|}{1.6} \\
\hline$\alpha_{1}$ & ○ & \multirow{2}{*}{\multicolumn{8}{|c|}{$\begin{array}{c}-5.57 \\
404.63\end{array}$}} & \multicolumn{4}{|c|}{0} \\
\hline$T_{01}$ & $\mathrm{~K}$ & & & & & & & & & \multicolumn{4}{|c|}{489} \\
\hline$p_{01}$ & $\mathrm{~Pa}$ & \multicolumn{8}{|c|}{$2.58 \cdot 10^{5}$} & \multirow{2}{*}{\multicolumn{4}{|c|}{$\begin{array}{l}11.2 \cdot 10^{5} \\
0.09 \cdot 10^{5}\end{array}$}} \\
\hline$p_{03}$ & $\mathrm{~Pa}$ & \multicolumn{8}{|c|}{$1.05 \cdot 10^{5}$} & & & & \\
\hline$s s$ & $\mathrm{~mm}$ & \multicolumn{2}{|c|}{235} & \multicolumn{2}{|c|}{200} & \multicolumn{2}{|c|}{195} & \multicolumn{2}{|c|}{180} & \multicolumn{4}{|c|}{300} \\
\hline$s s_{s t}$ & $\mathrm{~mm}$ & \multicolumn{2}{|c|}{610} & & 95 & \multicolumn{2}{|c|}{640} & 6 & 43 & 500 & & & 500 \\
\hline$(t / o)_{n},(t / o)_{r}$ & - & 0.0361 & 10.0302 & 0.0361 & 0.0284 & +0.0360 & 0.0267 & 0.0360 & 0.0249 & \multirow{2}{*}{\multicolumn{4}{|c|}{$\begin{array}{c}0.05^{(* *)} \\
0.2^{(* *)}\end{array}$}} \\
\hline$t_{c l}$ & $\mathrm{~mm}$ & & & & & 0.4 & & & & & & & \\
\hline
\end{tabular}

${ }^{(*)}=$ estimated value. ${ }^{(* *)}=$ assumed value with uncertainty.

Four-stage subsonic turbine. The first case study is a subsonic four-stage turbine operated with air whose design performance and flow characteristics are described in Kötzing and Evers [77] and in Hirsch and Denton [78]. The turbine generates $703 \mathrm{~kW}$ at $7500 \mathrm{rpm}$, has a total-to-static pressure ratio of approximately 2.6 and a calculated total-to-total efficiency of $91.3 \%$ with an estimated accuracy of $0.8 \%$ [77, 79]. The blades are of the free-vortex type, designed for a $50 \%$ degree of reaction in the middle section. Kötzing and Evers [77] suggested the presence of uncertainty in the experimental data. In order to improve the reliability of the validation, the results of TURAX were also compared to the Computational Fluid-Dynamic (CFD) data documented in Gerolymos and Hanisch [80] and Croce et al. [81]. These two are representative of state-of-the-art modelling techniques for multistage turbines [80-82] and have been validated using other experimental turbomachinery data [83, 84].

Table 5 lists the input data used for model validation. Blade opening, pitch, statorrotor axial clearance and interstage axial gap at the mean-line section were extracted by interpolation from the design data in the references. The axial velocity at the turbine inlet was computed by mass and energy balances. Flow coefficients were found by obtaining the actual turbine mean-line diameter and the best possible match with the actual blade height at the stage outlet. A straight blade profile in the rear suction side after the opening and a surface roughness of $2 \cdot 10^{-3} \mathrm{~mm}$ were used in the calculations. Thermodynamic and flow conditions at the different turbine sections used for the comparison were estimated by applying mass-weighted averages to the experimental and CFD profiles, except for the pressure that was estimated as an area-weighted average. The thermodynamic properties of air were computed using REFPROP [86]. 
Two-stage ORC turbine. The second reference case for the validation of the multistage turbine model is a supersonic two-stage turbine used for a small demonstration solar power plant, whose design data and test results are presented by Verneau [24, 85] and Boy-Marcotte [87]. The turbine features a first, highly-loaded impulse stage with converging-diverging nozzle blades, and a second stage with $50 \%$ reaction blading. The fluorochemical FC-75 is employed as the working fluid and the turbine produces approximately $54 \mathrm{~kW}$ at $7700 \mathrm{rpm}$ with a measured total-to-static efficiency of $78 \%$.

Table 5 shows the input data used in the validation of TURAX. Since the blade angle at the first rotor outlet was not provided, the actual value of the flow angle $56.7^{\circ}$ was imposed in order to limit the uncertainty of preliminary calculations. The stage loading coefficients in the two stages were selected in order to match the actual mean radius and peripheral speed. The geometric data that were not provided by Verneau were assumed as indicated in Table 5. Opening-to-pitch ratios in the first stage nozzle and in the second stage were estimated using the cosine rule of the mean-line exit flow angles given in Ref. [24]. The throat at the nozzle and rotor exit in the second stage were computed based on the assumed values of opening-to-pitch and the known pitch. Trailing edge to opening ratios and tip clearance were assumed as in Macchi [71]. The axial velocity at the turbine inlet was computed by mass and energy balances. A straight blade profile in the rear suction side after the throat and a surface roughness of $2 \cdot 10^{-3} \mathrm{~mm}$ were used. The thermodynamic properties of FC-75 were computed using the Peng-Robinson equation of state. The critical properties of FC-75 were used as in Kluwick [88] and the ideal molar heat capacity coefficients were estimated with the method by Joback and Reid [89]. The ideal molar heat capacity $c_{p}$, expressed in $J \cdot \mathrm{mol}^{-1} \cdot \mathrm{K}^{-1}$, was computed as a fourth-degree polynomial function of temperature with coefficients $\mathrm{A}=-230.11, \mathrm{~B}=2.6724, \mathrm{C}=-0.0034$, and $\mathrm{D}=2.00 \cdot 10^{-6}$.

The uncertainty analysis using the Monte Carlo method [90] was carried out on the assumed parameters in order to evaluate the effect of their uncertainty on the results. The 6 uncertain parameters and their assumed values are indicated in Table 5. They were varied in the range $\pm 10 \%$, which was selected to yield less than $5^{\circ}$ of flow deviation at the rotor outlet in the second stage and at the nozzle outlet in the first stage, as expected for the type of blading employed in the test case [91]. A number of 500 samples was used for each variable, and a uniform distribution without correlation control was applied. A model in the Matlab environment originally developed by Sin et al. [92] and modified for the scope of this work was used.

\subsection{Design optimization}

In this work, turbine and cycle models were combined and optimized following the iterative procedure illustrated in Figure 1 and described in Sec. 2. The optimization boundaries are described in La Seta et al. [18]. However, the approach in [18] was based on the use of a surrogate model for the turbine, whereas a new approach was adopted in this study since it does not require the computational efforts of generating numerous design points for each fluid and number of stages. The objective function of the cycle and turbine optimizations are the net power output and the turbine efficiency, 
respectively, defined as

$$
P_{n e t}=\dot{m}_{w f}\left(\Delta h_{0, t}-\Delta h_{0, p}\right), \quad \eta=\frac{\Delta h_{0, t}}{\Delta h_{t s}-0.5 \cdot \frac{C_{a 3}{ }^{2}}{2}}
$$

The parameter $\dot{m}_{w f}$ is the working fluid mass flow rate, and $\Delta h_{0, t}$ and $\Delta h_{0, p}$ are the total-to-total enthalpy drops across the turbine and the pump, respectively. The term $\Delta h_{t s}$ denotes the total-to-static isentropic enthalpy drop across the turbine, and the coefficient 0.5 indicates that $50 \%$ of the kinetic energy is assumed to be recovered by a diffuser downstream the last stage. Cycle and turbine designs were optimized by means of a hybrid optimization approach combining Particle Swarm optimization with a direct search method. A population size of 2000 and 500 for cycle and turbine were selected, since they provided a good compromise between accuracy and computational time. The turbine was designed considering the cases of optimized and fixed rotational speed. If the optimal rotational speed was lower or equal to that required by the generator (3600 rpm aboard the ship), the gearbox was not used and the rotational speed was fixed to the value 3600,1800 or $1200 \mathrm{rpm}$. A maximum value of $500 \mathrm{~m} / \mathrm{s}$ for the rotor blade tip speed was imposed as the optimization constraint, in order to limit mechanical stress issues.

\section{Results}

\subsection{Validation}

Four-stage subsonic turbine. Table 6 shows the results of the validation. The deviation between experimental and TURAX values is expressed as Dev $=(T U R A X-$ datum)/datum, where datum refers to the corresponding experimental value. When experimental data are not available for comparison or are considered uncertain, the deviation is calculated with respect to the CFD data by Gerolymos et al. [80] and Croce et al. [81]. The deviation in the flow angles is expressed in absolute difference. The total pressure and temperature at the outlet of the different stages, $p_{03}$ and $T_{03}$, show good agreement with experimental and CFD data, with deviations smaller than $0.5 \%$. The deviation in static pressure $p_{3}$ is higher and up to $1.7 \%$. Notwithstanding the lack of reliable velocity data in the experimental results, the comparison between TURAX and CFD calculations of Croce at al. [81] shows a maximum discrepancy of $3.5 \%$ in absolute velocity $C_{3}$, possibly due to the discrepancy in static pressure. Although experimental data of the rotor outlet relative flow angle $\beta_{3}$ were not provided, the comparison with the CFD data of Gerolymos et al. [80] suggests agreement within $3^{\circ}$. The absolute flow angle at the rotor outlet $\alpha_{3}$ has a deviation up to $8^{\circ}$ with experimental data. This high value might stem from the discrepancy in $C_{3}$. Figure 3 shows the profiles of the main quantities at the exit of each stage. Despite the difference between the experimental and predicted velocity profiles, the average values of TURAX provide a reasonable match with the CFD profiles. Figure 4 shows the meridional turbine layout obtained with TURAX. The blade heights are computed with good accuracy, with less than $3 \%$ deviation, as a result of the relatively small discrepancies in the flow and thermodynamic quantities. The predicted total-to-total efficiency of the stages resulted to be within $0.2 \%$-points of the CFD values, and within $1.72 \%$-points of the 
Table 6: Comparison of results obtained with TURAX, CFD, and experimental investigations [77, 78] on the four-stage Hannover turbine.

\begin{tabular}{|c|c|c|c|c|c|c|c|c|c|}
\hline \multirow[t]{2}{*}{ Symbol } & \multirow[t]{2}{*}{ Units } & Exp. data & TURAX & CFD & Dev. & Exp. data & TURAX & CFD & Dev. \\
\hline & & \multicolumn{4}{|c|}{ Stage 1} & \multicolumn{4}{|c|}{ Stage 2} \\
\hline$T_{03}$ & $\mathrm{~K}$ & 384.81 & 384.60 & $382.72^{(*)}$ & $0.05 \%$ & 363.12 & 363.43 & $362.13^{(*)}$ & $-0.09 \%$ \\
\hline$p_{03}$ & $\mathrm{~Pa}$ & $2.12 \cdot 10^{5}$ & $2.11 \cdot 10^{5}$ & $2.09 \cdot 10^{5(*)}$ & $0.32 \%$ & $1.70 \cdot 10^{5}$ & $1.70 \cdot 10^{5}$ & $1.69 \cdot 10^{5(*)}$ & $-0.02 \%$ \\
\hline$p_{3}$ & $\mathrm{~Pa}$ & $2.07 \cdot 10^{5}$ & $2.08 \cdot 10^{5}$ & & $-0.62 \%$ & $1.66 \cdot 10^{5}$ & $1.67 \cdot 10^{5}$ & & $-0.91 \%$ \\
\hline$C_{3}$ & $\mathrm{~m} / \mathrm{s}$ & 73.33 & 57.96 & $59.78^{(* *)}$ & $3.05 \%$ & 73.0 & 60.02 & $60.19^{(* *)}$ & $0.28 \%$ \\
\hline$\beta_{3}$ & & & 65.93 & $65.85^{(* *)}$ & 0.08 & & 66.62 & $66.97^{(* *)}$ & -0.35 \\
\hline$\alpha_{3}$ & & 0.62 & -3.47 & $4.65^{(*)}$ & 4.10 & -4.76 & 2.30 & $6.67^{(*)}$ & -7.06 \\
\hline$h 1$ & $\mathrm{~m}$ & 0.0595 & 0.0594 & & $0.17 \%$ & 0.0675 & 0.0682 & & $-1.04 \%$ \\
\hline$h_{21}$ & $\mathrm{~m}$ & 0.0635 & 0.0635 & & $0.00 \%$ & 0.0725 & 0.0736 & & $-1.52 \%$ \\
\hline$h_{3}$ & $\mathrm{~m}$ & 0.0675 & 0.0682 & & $-1.04 \%$ & 0.0775 & 0.0766 & & $1.16 \%$ \\
\hline DR & - & & 0.347 & n.a. & & & 0.4269 & & \\
\hline \multirow[t]{2}{*}{$\eta_{s t}$} & - & $89.91 \%$ & $91.49 \%$ & $91.45 \%(*)$ & $0.0 \%$ & $92.52 \%$ & $92.22 \%$ & $92.10 \%(*)$ & $0.1 \%$ \\
\hline & & \multicolumn{4}{|c|}{ Stage 3} & \multicolumn{4}{|c|}{ Stage 4} \\
\hline$T_{03}$ & $\mathrm{~K}$ & 340.377 & 341.95 & $341.40^{(*)}$ & $-0.46 \%$ & 321.034 & 320.23 & $319.57^{(*)}$ & $0.25 \%$ \\
\hline$p_{03}$ & $\mathrm{~Pa}$ & $1.35 \cdot 10^{5}$ & $1.35 \cdot 10^{5}$ & $1.36 \cdot 10^{5(* *)}$ & $-0.18 \%$ & $1.05 \cdot 10^{5}$ & $1.05 \cdot 10^{5}$ & $1.05 \cdot 10^{5}(*)$ & $-0.17 \%$ \\
\hline$p_{3}$ & $\mathrm{~Pa}$ & $1.31 \cdot 10^{5}$ & $1.32 \cdot 10^{5}$ & & $-1.06 \%$ & $1.01 \cdot 10^{5}$ & $1.03 \cdot 10^{5}$ & & $-1.70 \%$ \\
\hline$C_{3}$ & $\mathrm{~m} / \mathrm{s}$ & 73.193 & 60.79 & $60.33^{(* *)}$ & $-0.77 \%$ & 81.401 & 62.04 & $64.30^{(* *)}$ & $3.52 \%$ \\
\hline$\beta_{3}$ & & & 67.40 & $67.04^{(* *)}$ & 0.36 & & 68.28 & $65.22^{(* *)}$ & 3.06 \\
\hline$\alpha_{3}$ & & -2.159 & 4.39 & $4.70^{(*)}$ & 6.55 & -0.608 & 7.35 & $-0.57^{(*)}$ & -7.96 \\
\hline$h 1$ & $\mathrm{~m}$ & 0.0775 & 0.0767 & & $1.03 \%$ & 0.0892 & 0.0885 & & $0.78 \%$ \\
\hline$h_{21}$ & $\mathrm{~m}$ & 0.0833 & 0.0846 & & $-1.50 \%$ & 0.0961 & 0.0988 & & $-2.81 \%$ \\
\hline$h_{3}$ & $\mathrm{~m}$ & 0.0892 & 0.0885 & & $0.78 \%$ & 0.1030 & 0.1026 & & $0.39 \%$ \\
\hline DR & - & & 0.47 & & & & 0.54 & & \\
\hline$\eta_{s t}$ & - & $\mathrm{n} / \mathrm{a}$ & $92.55 \%$ & $92.80 \%^{(*)}$ & $0.2 \%$ & $\mathrm{n} / \mathrm{a}$ & $92.94 \%$ & $92.73 \%(* *)$ & $0.2 \%$ \\
\hline$\eta_{t t}$ & - & $91.3 \%$ & $93.02 \%$ & $92.96 \%$ & $1.72 \mathrm{pp}$ & & & & \\
\hline
\end{tabular}

experimental values. The results of this validation are considered to be satisfactory and confirm that TURAX is suitable for the preliminary design and performance prediction of multistage turbine architectures featuring subsonic flow conditions and high-aspect ratio blade profiles.

Two-stage supersonic ORC turbine. Table 7 reports the results of the validation with the two-stage ORC turbine described by Verneau [24, 85]. The values of standard deviation obtained with the uncertainty analysis are shown in absolute terms. The thermodynamic and flow quantities in the two stages show a good agreement with the data of Verneau, with deviations up to $3 \%$ in the first stage and $8.5 \%$ in the second stage. Static pressure and absolute Mach number at the first and the second stage outlet, respectively, show a mismatch up to $6.3 \%$ which is possibly related to the discrepancy in the velocity values. Figure 4 shows the meridional profile of the turbine computed by TURAX (red) and the original profile (black) from Verneau [24]. Blade heights and number of blades are calculated with less than $3 \%$ deviation except at the turbine outlet, where the deviation is up to $5.6 \%$. TURAX computed total-to-static efficiency values of $73.22 \%$ and $81.53 \%$ for the first and the second stage, respectively. The predicted efficiency was $79.76 \%$ and differed by $1.76 \%$-points from the experimental value of Verneau. Figure 5 shows the scatter plot of turbine efficiency after uncertainty 
Stage 1
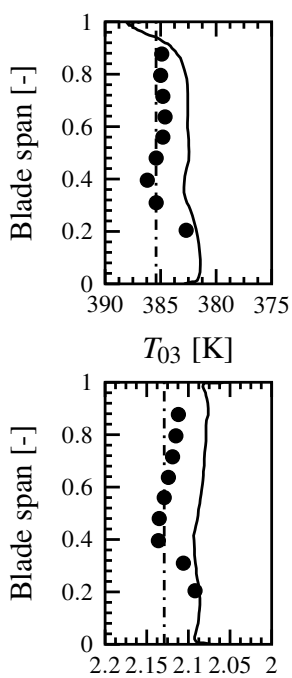

$p_{03}[\mathrm{~Pa}]_{10^{5}}$

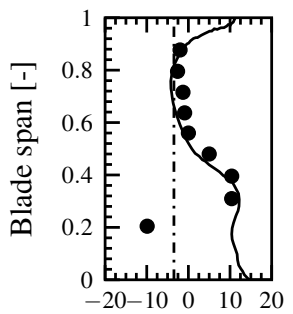

$\alpha_{3}\left[{ }^{\circ}\right]$

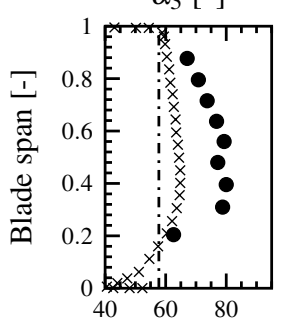

$C_{3}[\mathrm{~m} / \mathrm{s}]$
Stage 2
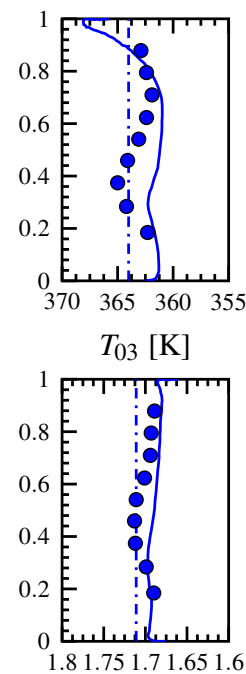

$p_{03}[\mathrm{~Pa}]_{10^{5}}$

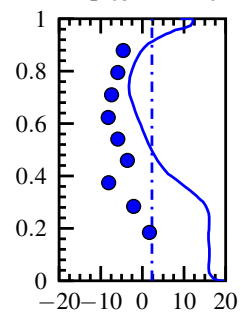

$\alpha_{3}\left[{ }^{\circ}\right]$

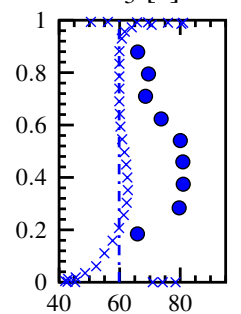

$C_{3}[\mathrm{~m} / \mathrm{s}]$
Stage 3
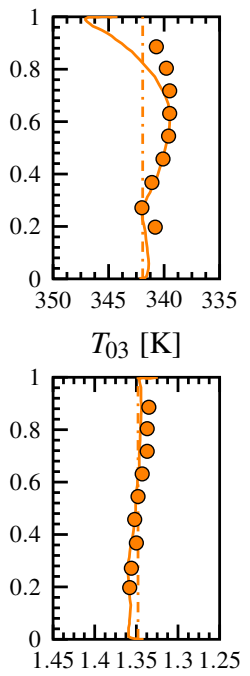

$p_{03}[\mathrm{~Pa}]_{10^{5}}$

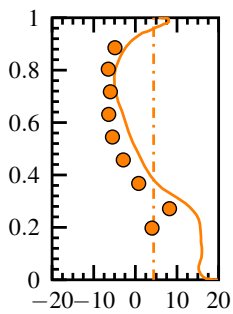

$\alpha_{3}\left[{ }^{\circ}\right]$

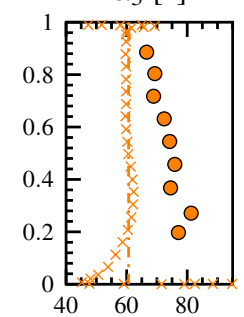

$C_{3}[\mathrm{~m} / \mathrm{s}]$
Stage 4
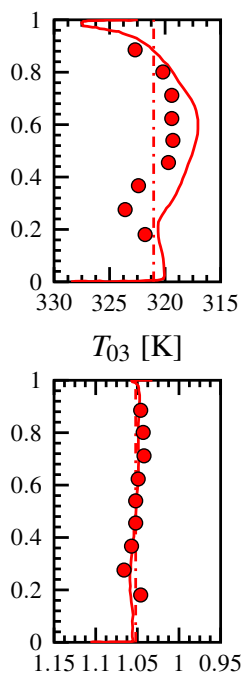

$p_{03}[\mathrm{~Pa}]_{10^{5}}$

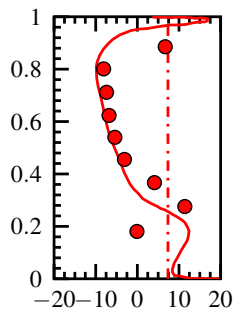

$\alpha_{3}\left[{ }^{\circ}\right]$

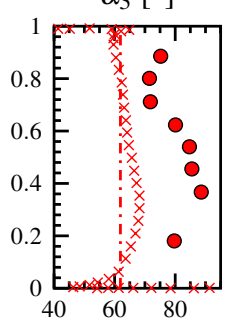

$C_{3}[\mathrm{~m} / \mathrm{s}]$

Gerolymos et al. $\times$ Croce et al. $\bullet$ Exp. -.-. TURAX

Figure 3: Profiles of total temperature, total pressure, absolute flow angle, absolute velocity at the stage outlet. Data from experimental results [77], Gerolymos et al. [80], Croce at al. [81] and TURAX for the Hannover turbine test case.

propagation and the ranking of the uncertain parameters. The parameters with a greater impact on the results were the opening-to-pitch ratio, responsible for the calculation of 


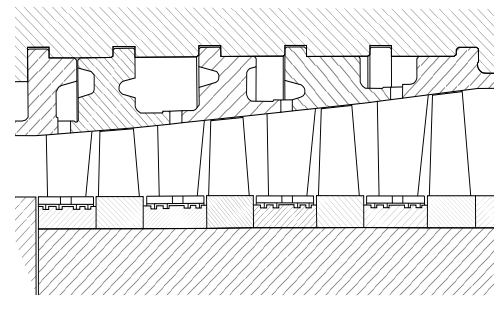

(a)

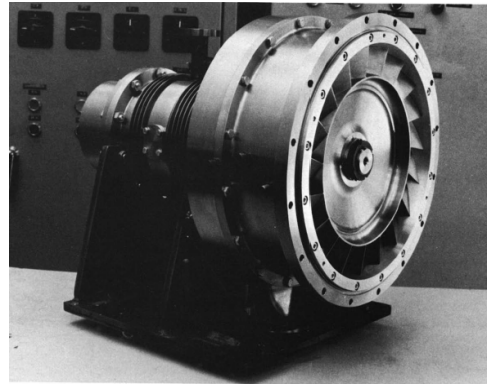

(c)

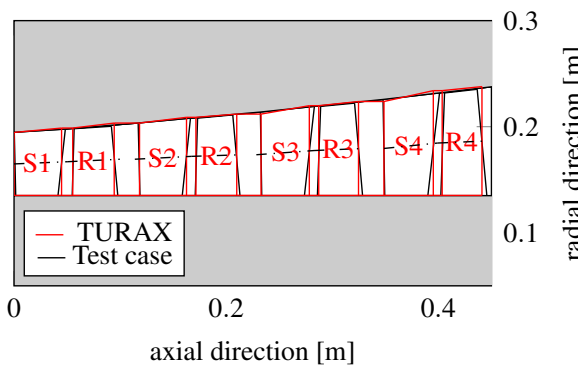

(b)

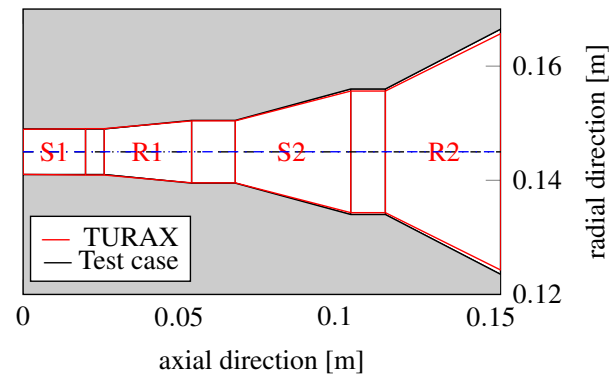

(d)

Figure 4: (a) Subsonic turbine test case (adapted from [77]); (b) meridional cut layout of the subsonic turbine; (c) supersonic ORC turbine test case [87]; (d) meridional cut layout of the supersonic ORC turbine.

the exit flow angle, and the blade surface roughness, responsible for frictional effects on the blades. The stage inlet flow angle, tip clearance, trailing edge thickness-to-opening ratio and backbone surface curvature provided only a marginal change in efficiency. Moreover, the data of Verneau are in many cases comprised in the standard deviation range of TURAX. In light of the complexity of phenomena related to the design of a two-stage supersonic turbine with an organic fluid, the obtained discrepancy of less than $2 \%$-points is considered satisfactory for a preliminary design tool.

\subsection{Design optimization}

Figure 8 shows the cycle net power output, Figure 9 the turbine efficiency and Figure 10 the minimum required number of stages obtained by the optimization for both the conservative and the advanced approaches.

Figure 8 highlights that different values of net power output can be obtained depending on turbine modelling criteria and configurations. For the fluid MM, the adoption of the methodology presented in this work results in unfeasible design solutions for one and two stages. Feasible solutions are found using three stages with the advanced design and five stages in the case a conservative approach is preferred. Different values of net power output are obtained when the turbine is optimized together with the cycle. 
Table 7: Comparison of results between TURAX and Verneau $[24,85]$ data on a two-stage ORC turbine.

\begin{tabular}{|c|c|c|c|c|c|c|c|c|c|}
\hline \multirow[b]{2}{*}{ Parameter } & \multirow[b]{2}{*}{ Units } & \multicolumn{3}{|c|}{ Stage 1} & \multicolumn{3}{|c|}{ Stage 2} & \multirow[b]{2}{*}{ St.dev. } & \multirow[b]{2}{*}{ Dev. } \\
\hline & & Verneau & TURAX & St.dev. & Dev. & Verneau & TURAX & & \\
\hline$\alpha_{2}$ & $\circ$ & 74 & 73.99 & 0.95 & 0.00 & 60 & 58.87 & 2.44 & 1.12 \\
\hline$\beta_{2}$ & $\circ$ & 59.20 & 59.55 & 1.56 & 0.36 & -33 & -29.24 & 8.54 & 3.75 \\
\hline $\mathrm{Ca}_{2}$ & $\mathrm{~m} / \mathrm{s}$ & 65 & 65.46 & 4.11 & $0.7 \%$ & 49 & 53.16 & 7.72 & $8.5 \%$ \\
\hline$C_{2}$ & $\mathrm{~m} / \mathrm{s}$ & 235 & 237.41 & 1.39 & $1.0 \%$ & 98 & 102.56 & 9.42 & $4.7 \%$ \\
\hline$W_{2}$ & $\mathrm{~m} / \mathrm{s}$ & 126 & 129.15 & 2.2 & $2.5 \%$ & 58.5 & 61.38 & 4.9 & $5.0 \%$ \\
\hline$M_{2}$ & - & 2.45 & 2.48 & 0.014 & $2.5 \%$ & 1.02 & 1.06 & 0.1 & $4.9 \%$ \\
\hline$M_{w 2}$ & - & 1.32 & 1.35 & 0.02 & $2.4 \%$ & 0.61 & 0.64 & 0.05 & $5.0 \%$ \\
\hline$p_{2}$ & $\mathrm{~Pa}$ & $3.08 \cdot 10^{4}(*)$ & $3.00 \cdot 10^{4}$ & 996 & $-2.9 \%$ & 15292 & $1.43 \cdot 10^{4}$ & 1650 & $-6.3 \%$ \\
\hline$T_{2}$ & $\mathrm{~K}$ & $459.40^{(*)}$ & 458.79 & 0.25 & $-0.1 \%$ & 457.15 & 457.14 & 0.74 & $-0.1 \%$ \\
\hline$W_{3}$ & $\mathrm{~m} / \mathrm{s}$ & 130 & 127.76 & 0 & $-1.7 \%$ & 118 & 116.57 & 6.76 & $-1.2 \%$ \\
\hline $\mathrm{Ca}_{3}$ & $\mathrm{~m} / \mathrm{s}$ & 71 & 70.14 & 0 & $-1.2 \%$ & 49 & 49.1 & 0 & $0.2 \%$ \\
\hline$C_{3}$ & $\mathrm{~m} / \mathrm{s}$ & 72 & 70.87 & 0 & $-1.6 \%$ & 49 & 50.89 & 1.64 & $3.9 \%$ \\
\hline$M_{w 3}$ & - & 1.35 & 1.33 & 0 & $-1.3 \%$ & 1.24 & 1.22 & 0.07 & $-1.7 \%$ \\
\hline$M_{3}$ & - & 0.75 & 0.74 & 0 & $-1.5 \%$ & 0.51 & 0.53 & 0.02 & $3.8 \%$ \\
\hline$\beta_{3}$ & $\circ$ & 56.7 & 56.7 & 0 & 0.00 & 65 & 65 & 1.55 & -0.01 \\
\hline$\alpha_{3}$ & $\circ$ & -6.8 & -8.21 & 0 & -1.41 & -10 & -12.62 & 8.22 & -2.62 \\
\hline$T_{03}$ & $\mathrm{~K}$ & $461.23^{(*)}$ & 460.78 & 0.06 & $-0.1 \%$ & 454.11 & 454.38 & 0.1 & $0.1 \%$ \\
\hline$T_{3}$ & $\mathrm{~K}$ & $459.77^{(*)}$ & 458.86 & 0.06 & $-0.2 \%$ & 453.2 & 453.4 & 0.09 & $0.0 \%$ \\
\hline$p_{3}$ & $\mathrm{~Pa}$ & $2.24 \cdot 10^{4}$ & $2.1 \cdot 10^{4}$ & 0.74 & $-6.3 \%$ & 7900 & $7.78 \cdot 10^{3}$ & 72.1 & $-1.5 \%$ \\
\hline$p_{03}$ & $\mathrm{~Pa}$ & $2.76 \cdot 10^{4}(*)$ & $2.77 \cdot 10^{4}$ & 0 & $0.1 \%$ & 9021.9 & $8.98 \cdot 10^{4}$ & 0 & $-0.5 \%$ \\
\hline$h_{1}$ & $\mathrm{~m}$ & 0.008 & 0.0079 & 0 & $1.3 \%$ & 0.011 & 0.0109 & 0 & $1.2 \%$ \\
\hline$h_{2}$ & $\mathrm{~m}$ & 0.008 & 0.0082 & 0 & $-2.1 \%$ & 0.022 & 0.0214 & 0.001 & $2.8 \%$ \\
\hline$h_{3}$ & $\mathrm{~m}$ & 0.011 & 0.0109 & 0 & $1.3 \%$ & 0.043 & 0.0415 & 0 & $3.4 \%$ \\
\hline$z_{n}$ & - & 25 & 27 & 1 & 2.00 & 30 & 30 & 2 & 0.46 \\
\hline$z_{r}$ & - & 121 & 122 & 0 & 1 & 19 & 20 & 1 & 1 \\
\hline DR (theor.) & - & 0.086 & 0.093 & 0.009 & 0.01 & 0.50 & 0.47 & 0.09 & -0.03 \\
\hline Power & $\mathrm{kW}$ & 40 & 40.78 & 0.089 & $-2.0 \%$ & 14 & 14.28 & 0.14 & $-2.0 \%$ \\
\hline$\eta_{s t}$ & - & $75 \%$ & $73.21 \%$ & $0.29 \mathrm{pp}$ & $1.8 \mathrm{pp}$ & $82 \%$ & $80.96 \%$ & $1.25 \mathrm{pp}$ & $1 \mathrm{pp}$ \\
\hline$\eta_{t}$ & - & $78 \%$ & $79.72 \%$ & $0.40 \mathrm{pp}$ & $1.76 \mathrm{pp}$ & & & & \\
\hline
\end{tabular}

$\left(^{*}\right)$ computed from the design point velocity triangles. St.dev. = standard deviation from the uncertainty analysis. $\mathrm{pp}=$ percentage-points.

From the thermodynamic perspective, n-butane ranks as the most promising candidate, followed by R245fa, isopentane and n-pentane. When the turbine design is optimized for constant rotational speed, the net power output declines in most of the cases, since the machine is not operating at the optimal specific speed. In this case, R245fa outperforms n-butane thanks to the lower optimal rotational speed (approximately 7200 rpm). When a conservative design approach is adopted, almost all solutions except MM require two or three stages, with turbine efficiencies between $85 \%$ and $93 \%$ in most cases. Not much difference is observed in the required number of stages with optimized or constant rotational speed, except for n-pentane and n-butane due to the higher values of rotational speed between 9000 and $14000 \mathrm{rpm}$. The adoption of an advanced design approach always leads to optimal turbines featuring a single stage. In the case of MM, it is not possible to find suitable design solutions for one stage, primarily due to the excessive flaring angles and relative Mach numbers at the stage exit. The advantages of increasing the rotational speed with a gearbox might be offset by the additional efficiency penalty and the cost due to the insertion of such a component. 


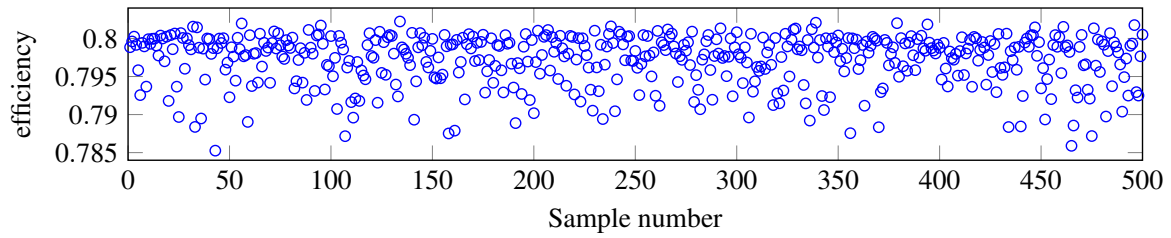

(a)

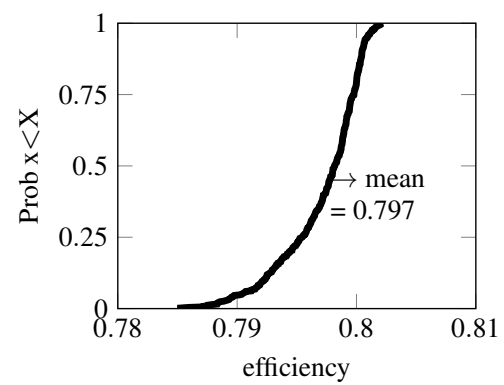

(b)

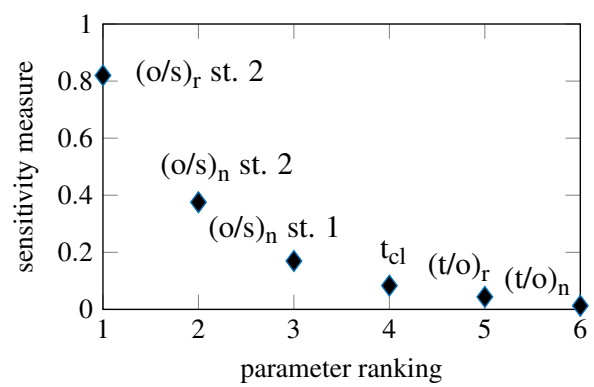

(c)

Figure 5: Results of the uncertainty analysis on the assumed parameters of the two-stage supersonic turbine: (a) scatterplot of uncertainty in turbine efficiency; (b) corresponding cumulative distribution function; (c) ranking of the uncertain parameters based on significance level.

The results suggest that the different power output values correspond to different turbine designs and that might lead to different levels of cost and complexity. Therefore, a dedicated analysis must be performed in order to identify whether one design solution outperforms another, considering both technical and economic criteria.

\subsection{Cycle-turbine performance index}

It is useful to compare the solutions of Figure 8 on a common basis in order to find the most suitable working fluid for the considered application. In this respect a figure of merit was used, which enables one to consider at the same time a) the higher system complexity resulting from the increased number of stages; b) the cost of the expander based on its size; and c) the possible cost of the gearbox. A Performance Index (PI) is defined here as the ratio of the electrical net power output to the cost of the turbogenerator unit:

$$
P I=\frac{P_{e l}}{C_{t u r b}} \quad\left[k W_{e l} / k €_{t}\right]
$$

where $P_{e l}=P_{\text {net }} \cdot \eta_{\text {gear }} \cdot \eta_{\text {gen }}$ is the net electrical power output of the cycle, considering the generator efficiency $\eta_{\text {gen }}$ and, possibly, the gearbox efficiency $\eta_{\text {gear }}$. The variable $C_{\text {turb }}$ denotes the cost of the turbogenerator in k€. The use of the turboexpander cost in the denominator is justified by the fact that the turbine represents between $15 \%$ and $70 \%$ of the total cost in the ORC system [13, 93-97] depending on power output, heat source temperature and system architecture. In this work, the cost of the turbogenerator 
was estimated using the correlation by Astolfi et al. [13], which was developed based on the experience gained by the authors with ORC manufacturers. The formula is valid for a power output higher than $1000 \mathrm{~kW}$, which applies to the designs in this paper. Equation 4 shows the total cost of the turbogenerator unit, expressed as the sum of the turbine cost $\left(C_{t}\right)$, generator cost $\left(C_{\text {gen }}\right)$ and possible gearbox cost $\left(C_{\text {gear }}\right)$. The parameter $n$ is the number of stages, SP is the size parameter of the last stage, $S P_{0}$ the reference turbine size parameter, $C_{0}$ the basic reference cost, and $P_{e l, 0}$ the reference turbine electric power.

$$
\begin{aligned}
& C_{\text {turb }}=C_{t}+C_{\text {gen }}+C_{\text {gear }} \\
& C_{t}=C_{0}\left(\frac{n}{n_{0}}\right)^{0.5}\left(\frac{S P}{S P_{0}}\right)^{1.1} \\
& C_{0}=1230 \mathrm{k} €, n_{0}=2, S P_{0}=0.18 \mathrm{~m} \\
& C_{g e n}=C_{0}\left(\frac{P_{e l}}{P_{e l, 0}}\right)^{0.67} \\
& C_{0}=200 \mathrm{k} €, P_{e l, 0}=5000 \mathrm{~kW} \\
& C_{\text {gear }}=0.4 \cdot C_{\text {gen }}
\end{aligned}
$$

Figure 6 shows the values of PI of the optimal solutions for each fluid, and Table 8 shows the characteristics of the obtained solutions.

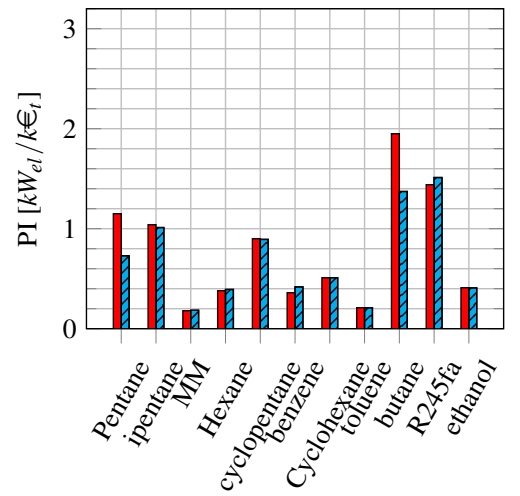

$\square$ gearbox $\square \square$ no gearbox

(a)

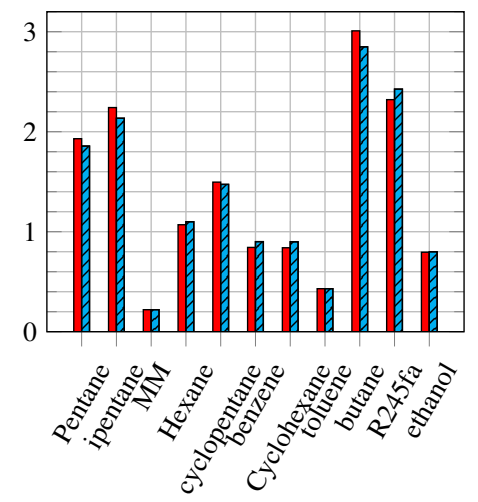

$\square$ gearbox $\square \square$ no gearbox

(b)

Figure 6: Performance Index (PI) of the working fluid candidates according to (a) the conservative and $(b)$ the advanced design approaches.

In both the conservative and the advanced approaches, the ORC systems with the highest PI would employ n-butane, but would feature a two-stage and a single-stage turbine with gearbox, respectively.

The fluid n-butane has the smallest turbine diameter, and results in the lowest cost, followed by R245fa. The working fluids yielding large turbine sizes and more stages 
Table 8: Ranking of the optimal working fluid candidates.

\begin{tabular}{|c|c|c|c|c|c|c|c|c|c|c|c|}
\hline \multirow[t]{3}{*}{ Fluid } & & $N_{s t}$ & Gearbox & $\mathrm{N}$ & $r_{m}$ & $U_{t i p}$ & $P_{e l}$ & $C_{t u r b}$ & $p_{\max }$ & $p_{\min }$ & $\frac{\dot{Q}_{s c}}{\dot{O}}$ \\
\hline & {$\left[\frac{k W}{k €_{t}}\right]$} & - & - & {$[\mathrm{rpm}]$} & {$[\mathrm{m}]$} & {$\left[\frac{m}{s}\right]$} & {$\left[k W_{e l}\right]$} & {$\left[k €_{t}\right]$} & [bar] & [bar $]$ & {$[-]$} \\
\hline & \multicolumn{11}{|c|}{ Conservative Design } \\
\hline butane & 1.95 & 2 & yes & 14371 & 0.16 & 281.4 & 2203 & 1128 & 30.37 & 2.83 & 0.54 \\
\hline $\mathrm{R} 245 \mathrm{fa}$ & 1.51 & 2 & no & 3600 & 0.37 & 229.8 & 2210 & 1462 & 29.21 & 1.78 & 0.51 \\
\hline Pentane & 1.15 & 2 & yes & 9128 & 0.24 & 264.1 & 1909 & 1655 & 14.46 & 0.82 & 0.35 \\
\hline ipentane & 1.04 & 3 & yes & 7673 & 0.23 & 214.9 & 1985 & 1903 & 22.11 & 1.09 & 0.35 \\
\hline cyclopentane & 0.90 & 2 & yes & 7885 & 0.28 & 266.0 & 1706 & 1894 & 8.84 & 0.51 & 0.24 \\
\hline ethanol & 0.41 & 3 & yes & 5939 & 0.43 & 307.4 & 1431 & 3499 & 6.60 & 0.10 & 0.13 \\
\hline Hexane & 0.39 & 3 & no & 3600 & 0.51 & 193.7 & 1778 & 4530 & 5.59 & 0.25 & 0.32 \\
\hline Cyclohexane & 0.38 & 2 & no & 3600 & 0.52 & 242.8 & 1656 & 4377 & 4.05 & 0.16 & 0.23 \\
\hline benzene & 0.36 & 3 & no & 3600 & 0.46 & 204.4 & 1644 & 4511 & 4.24 & 0.16 & 0.19 \\
\hline toluene & 0.21 & 3 & no & 1800 & 0.96 & 177.8 & 1563 & 7345 & 1.93 & 0.05 & 0.19 \\
\hline \multirow[t]{2}{*}{ MM } & 0.18 & 5 & yes & 1200 & 1.09 & 194.5 & 1742 & 9454 & 2.53 & 0.07 & 0.41 \\
\hline & \multicolumn{11}{|c|}{ Advanced Design } \\
\hline butane & 3.01 & 1 & yes & 20647 & 0.16 & 312.62 & 2238 & 744 & 30.00 & 2.83 & 0.54 \\
\hline $\mathrm{R} 245 \mathrm{fa}$ & 2.43 & 1 & no & 3600 & 0.48 & 185.52 & 2191 & 903 & 29.21 & 1.78 & 0.51 \\
\hline ipentane & 2.24 & 1 & yes & 14362 & 0.20 & 337.16 & 1986 & 886 & 22.11 & 1.09 & 0.35 \\
\hline Pentane & 1.93 & 1 & yes & 11149 & 0.28 & 356.3 & 1890 & 980 & 14.63 & 0.82 & 0.35 \\
\hline cyclopentane & 1.50 & 1 & yes & 11313 & 0.26 & 323.55 & 1705 & 1135 & 8.82 & 0.51 & 0.24 \\
\hline Hexane & 1.10 & 1 & no & 3600 & 0.68 & 284.86 & 1769 & 1608 & 5.56 & 0.25 & 0.29 \\
\hline benzene & 0.90 & 1 & no & 3600 & 0.77 & 307.11 & 1590 & 1766 & 4.24 & 0.16 & 0.19 \\
\hline Cyclohexane & 0.90 & 1 & no & 3600 & 0.74 & 293.12 & 1669 & 1857 & 4.06 & 0.16 & 0.24 \\
\hline ethanol & 0.80 & 1 & no & 3600 & 1.21 & 458.84 & 1240 & 1551 & 6.60 & 0.10 & 0.13 \\
\hline toluene & 0.43 & 1 & no & 1800 & 1.92 & 325.16 & 1465 & 3368 & 1.93 & 0.05 & 0.19 \\
\hline MM & 0.22 & 1 & no & 1200 & 1.23 & 323.55 & 1805 & 8242 & 2.54 & 0.07 & 0.41 \\
\hline
\end{tabular}

such as MM, toluene and ethanol, are further penalized in the fluid rank. Figure 7 shows that single-stage turbines feature rotor blades with higher deflection and more compact size in the axial direction. On the other hand, the two-stage configurations allow a conservative design of sealing and bearings due to the lower rotational speed. Table 8 shows that the smaller number of stages of the advanced designs results in a higher PI, while the best solutions in the conservative approach have two and three stages. In particular, the five-stage turbine with $\mathrm{MM}$ is greatly penalized by the additional complexity. Moreover, turbine designs with more than three stages are unusual [38].

Notwithstanding the higher net electrical power output, the additional cost and efficiency penalty of the gearbox result in a lower PI for many fluids such as R245fa, $\mathrm{n}$-pentane, and n-hexane due to an efficiency increase lower than $4 \%$-points. On the other hand, a gearbox solution for $\mathrm{n}$-butane is beneficial since it provides a comparatively higher turbine efficiency by 6-7\%-points and a reduced number of stages. 

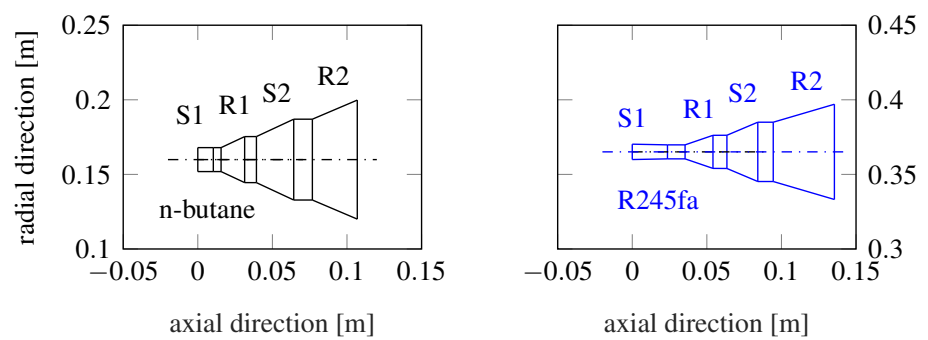

(a)
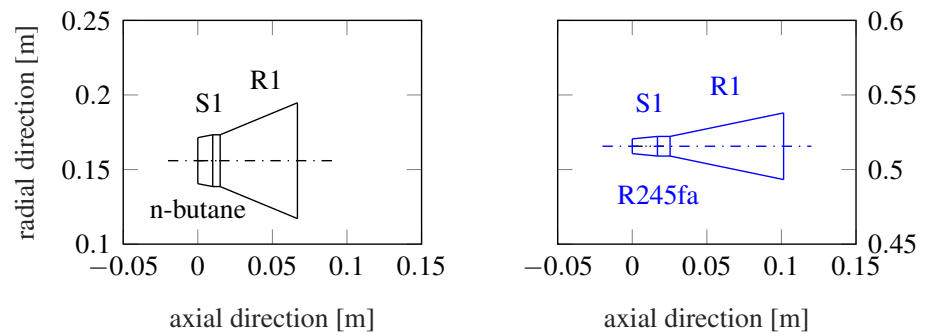

(b)

\begin{tabular}{|c|c|c|c|c|c|c|c|c|c|c|c|}
\hline \multirow[b]{2}{*}{ Stage } & \multirow[b]{2}{*}{ param } & \multicolumn{5}{|c|}{ Conservative design } & \multicolumn{5}{|c|}{ Advanced design } \\
\hline & & n-but. & $\mathrm{R} 245 \mathrm{fa}$ & n-pent. & isop. & cyclop. & n-but. & $\mathrm{R} 245 \mathrm{fa}$ & n-pent. & isop. & cyclop. \\
\hline \multirow[t]{3}{*}{1} & DR & 0.45 & 0.27 & 0.45 & 0.44 & 0.44 & 0.20 & 0.22 & 0.21 & 0.26 & 0.23 \\
\hline & $M_{2}$ & 1.18 & 1.40 & 1.27 & 1.18 & 1.26 & 1.86 & 1.96 & 2.23 & 2.07 & 2.01 \\
\hline & $M_{w 3}$ & 1.05 & 1.00 & 1.15 & 1.00 & 1.15 & 1.18 & 1.30 & 1.40 & 1.40 & 1.34 \\
\hline \multirow[t]{3}{*}{2} & DR & 0.53 & 0.38 & 0.50 & 0.44 & 0.52 & - & - & - & - & - \\
\hline & $M_{2}$ & 1.03 & 1.20 & 1.16 & 1.08 & 1.10 & - & - & - & - & - \\
\hline & $M_{w 3}$ & 1.09 & 1.07 & 1.15 & 0.97 & 1.16 & - & - & - & - & - \\
\hline \multirow[t]{3}{*}{3} & DR & - & - & - & 0.55 & - & - & - & - & - & - \\
\hline & $M_{2}$ & - & - & - & 0.93 & - & - & - & - & - & - \\
\hline & $M_{w 3}$ & - & - & - & 1.01 & - & - & - & - & - & - \\
\hline
\end{tabular}

Figure 7: Meridional profile geometry of the two best working fluid candidates, and Mach numbers and stage reactions of the five best working fluid candidates: (a) conservative and (b) advanced design approaches.

\section{Discussion}

The single-stage, highly supersonic n-butane turbine yielded the best PI value, which is approximately 1.5 times higher than that of the two-stage solution. Thus, 


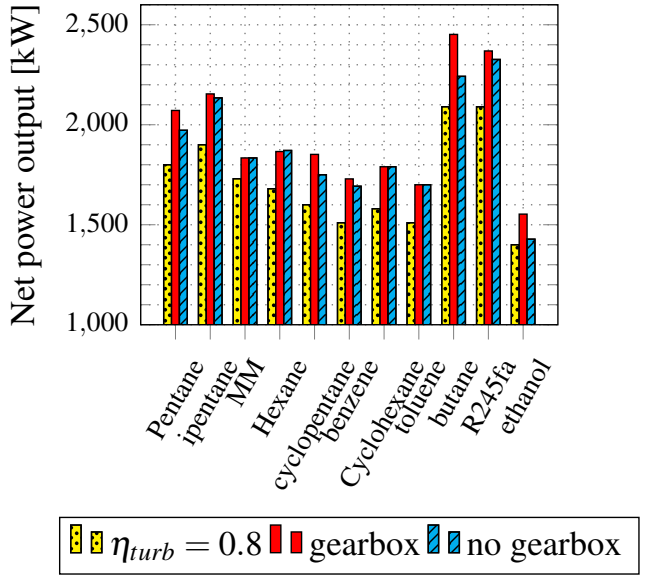

(a)

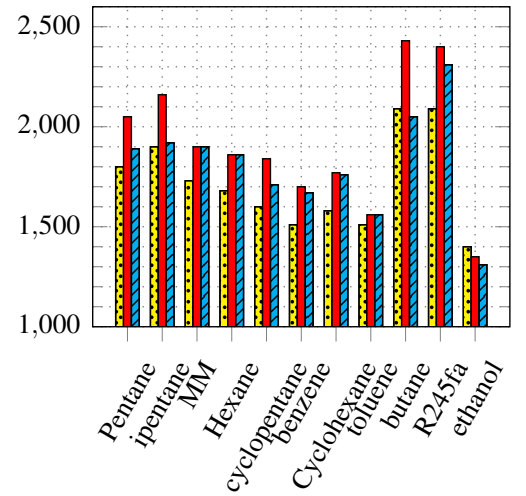

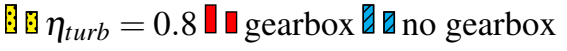

(b)

Figure 8: Optimal net power output of the working fluid candidates according to (a) the conservative and (b) the advanced design approaches.

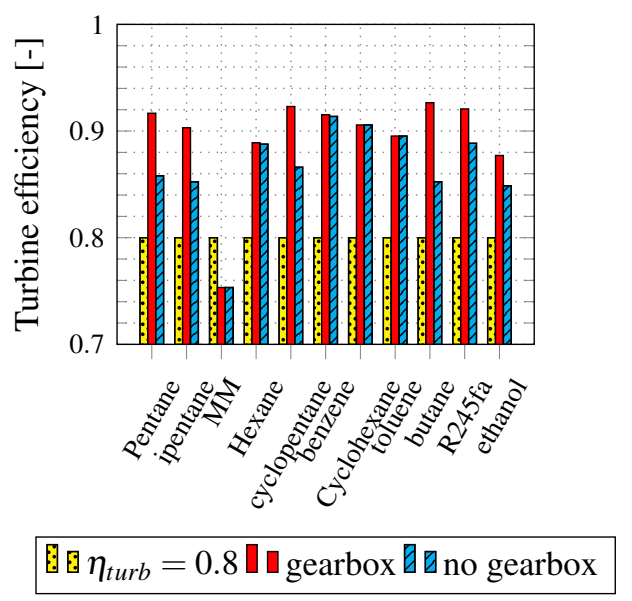

(a)

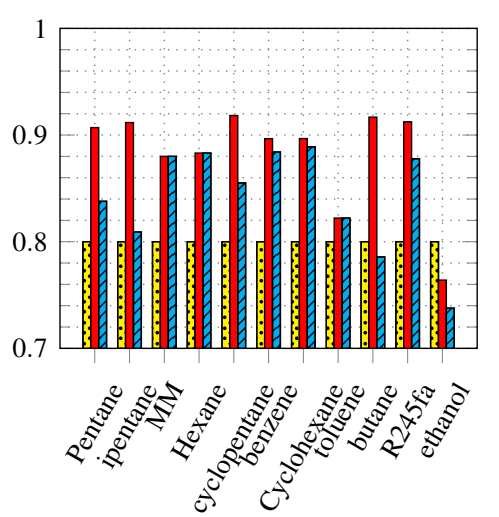

目 $\eta_{\text {turb }}=0.8 \square$ gearbox $⿴ 囗$ no gearbox

(b)

Figure 9: Turbine design efficiency of the working fluid candidates according to (a) the conservative and (b) the advanced design approaches.

the advanced approach would be the preferred option, provided that an aerodynamic design featuring supersonic concepts is accepted.

The review of the existing literature on single and multistage turbines suggests that the criteria for selecting the optimal number of stages depend on a multitude of 


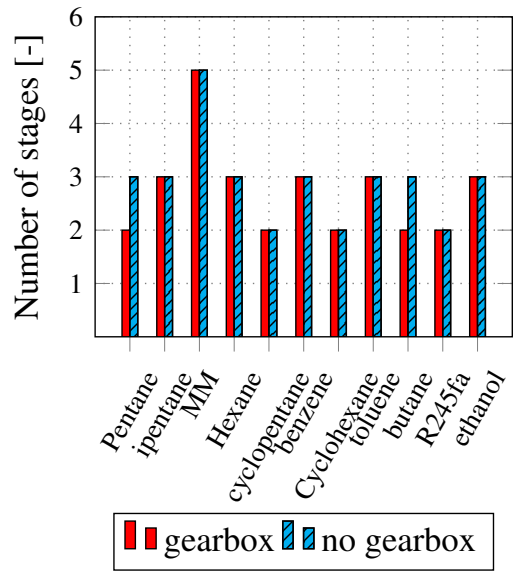

(a)
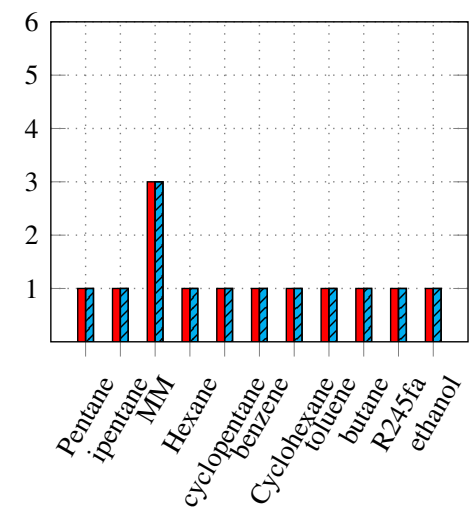

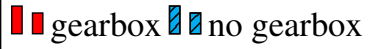

(b)

Figure 10: Minimum number of stages of the working fluid candidates according to (a) the conservative and (b) the advanced design approaches.

factors and on the requirements of the specific application. For example, Angelino et al. [23, 31] and Bado et al. [21] suggest that a conservative design approach was mainly followed between the 1970s and 1980s in Italy, see Table 1. The main rationale behind these designs was to prioritise high efficiency values at part load as well as to avoid the use of highly supersonic blade rows since loss models had, at that time, comparatively low reliability. Moreover, the higher number of stages could reduce the optimal rotational speed, thereby avoiding the use of a gearbox. Reaction blade profiles were employed in each stage, with a pressure ratio per stage estimated between 3.2 and 5.0. In terms of turbine efficiency, Angelino and Invernizzi [74] suggested the use of two-stage turbines instead of the single-stage one in order to obtain high performance and avoid excessive loading in the heat exchangers.

Notwithstanding the inherent challenges of more advanced designs, other authors documented the use of such high pressure ratio ORC turbines. Verneau [24] described the testing of different single and two-stage ORC turbines featuring pressure ratios between 6 and 150. An advanced design approach was considered here as the first stage stator was highly loaded and featured a converging-diverging nozzle with an exit Mach number up to 2.74. The relative inlet Mach number to the rotor was 1.1 or higher. The first stage pressure ratio was between 6 and 150 while the second was 2 or 3. For the two-stage turbines, Verneau [24] documented isentropic total-to-static turbine efficiencies of about 0.78 at the design point and a rapid performance decay at off-design operation.

Bronicki [98] reported his experience on designing and testing ORC turbines since 1960 and using high speed turbogenerator technology. Stator Mach numbers for singlestage units were between 2.5 and 3.5, indicating that an advanced design approach was followed. The overall stage efficiency for a $600 \mathrm{~W}$ unit was measured as 0.77 . 
Jokinen et al. [25] presented the results of a two-stage ORC axial turbine using toluene which was designed and tested in the late 1990s. The selection criteria of the number of stages were based on considerations from the work of Verneau [24]. The stage pressure ratio was above 100 , and the authors noted that a single-stage unit would have caused design problems and resulted in low efficiency at part-load due to the high blade deflection. The final design featured subsonic relative velocity to each blade passage inlet and supersonic flow conditions to the exit.

Osnaghi et al. [22] presented the design of an $8 \mathrm{~kW}$ two-stage ORC turbine with a pressure ratio of about 120 and conceived for a medium temperature solar power plant. To minimize the number of stages, an advanced design approach was adopted resulting in a two-stage turbine featuring converging-diverging nozzles with exit Mach numbers of about 1.9 and transonic rotors. The design value of thermodynamic efficiency calculated from measurements was approximately 0.7 , and the efficiency dropped rapidly when reducing the rotational speed.

The survey of the available literature suggests that the optimal n-butane turbine, having a pressure ratio of about 10.3, is in a range where two stages are required following the conservative design approach and one stage would be sufficient for the advanced design approach. This is in good agreement with the results obtained using the methodology presented here, further confirming the validity of the methodology. In fact, the values of isentropic efficiency estimated by the present model in the advanced design approach appear to be comparatively higher than those documented in the literature (i.e. $>90 \%$ ). This deviation might be due to the lack of fully reliable loss and deviation correlations for supersonic conditions. However, it needs to be stressed that there are inherent difficulties associated with the aerodynamic design of supersonic turbines. As a matter of fact, recent studies on ORC supersonic turbines by Pini et al. and Persico and Rodriguez-Fernandez and Persico [99, 100] have shown that novel CFD-based shape-optimization techniques allow for achieving consistent performance gains with respect to traditional aerodynamic design methods. These methods can also include multi-point turbine operation, thus minimizing the efficiency penalty at off-design conditions [38].

Besides aerodynamic difficulties, for supersonic turbines Horn [101] highlighted some possible challenges related to mechanical stresses on blades and on the bearing system, additional losses and centrifugal stresses on the blade due to the large rotor chords and flaring angles.

In the case where the design and operation of an advanced n-butane turbine are considered too problematic, R245fa can be the second best working fluid candidate, thanks to the relatively lower flow velocity (and hence Mach number) and rotational speed, allowing for a more conservative design of bearings and seals.

Regarding environmental aspects, the best fluid, n-butane, is highly flammable and has minor hazard issues. Until now, the use of flammable fluids is allowed in ORC plants, and they have been constructed and operated by many manufacturers. The fluid $\mathrm{R} 245 \mathrm{fa}$ is currently used by a number of ORC manufacturers (see Table 3); however, it should be phased out on a mid-term horizon due to the relatively high GWP [102]. The use of new working fluids such as R1233ZE(Z) and R1233zd(E) would represent ideal solutions from an environmental perspective, although they were discarded in the early selection step due to their low thermal stability limit for the considered application. 


\section{Conclusions}

This paper presented, for the first time in the literature, a methodology for the design of ORC power systems based on cycle and multistage turbine design criteria. In addition, it presented, for the first time, a mean-line model of an ORC multistage axial turbine that is validated and discussed, and two different design approaches for such turbines. The turbine model was developed and validated against a four-stage subsonic turbine and a two-stage supersonic ORC turbine, representative of a conservative and an advanced design approach, respectively. After a working fluid preselection process, a coupled optimization of cycle and turbine designs was performed for single and multistage turbine arrangements, which was then applied to the case study of waste heat recovery aboard large ships. The validation indicates overall satisfactory results in the comparison with the available data from the open literature, with $2 \%$-points prediction accuracy in efficiency, and up to $8.5 \%$ in flow conditions and design geometry.

The results suggest that taking into account the turbine design yields different solutions and choices. The turbine efficiency varies approximately between $74 \%$ and $93 \%$ when different fluids and design criteria are employed.

The fluid n-butane demonstrates the best trade-off between cycle and expander design. The results indicate that the optimal solution with n-butane features a single-stage configuration with highly supersonic flows, whereas it features a two-stage reaction turbine when a more conservative design approach is followed. These results are in agreement with the experimental findings of ORC multistage turbines documented in the literature and further confirm the validity of the presented methodology. The fluid R245fa resulted to be the second best fluid. Provided that its high GWP value is accepted, it can be used in place of n-butane since it is non-flammable and it has a lower optimal rotational speed than the expander designed with n-butane, which simplifies the design of bearings and sealings. Due to the additional cost for the systems, the adoption of a gearbox results in a better performance index only for those fluids, such as n-butane and n-pentane, where an increase of turbine efficiency up to 6-7\%-points is observed.

Finally it is noted that the methodology presented herein was limited to the design of the cycle and expander. For future work it would be relevant to address also offdesign conditions and include the performance of the heat exchangers and the pump. Moreover, it is recommended to employ advanced design techniques to investigate potential aerodynamic, structural, noise and off-design issues of highly supersonic turbines.

\section{Acknowledgments}

The research work was conducted within the frame of the THERMCYC project ("Advanced thermodynamic cycles utilizing low-temperature heat sources"; project ID: 1305-00036B, see http://www.thermcyc.mek.dtu.dk/) funded by InnovationsFonden, The Danish Council for Strategic Research in Sustainable Energy and Environment. The financial support is gratefully acknowledged. 


\section{References}

[1] H. Tabor, L. Bronicki, Establishing criteria for fluids for small vapor turbines, in: SAE National Transportation, Powerplant, and Fuels and Lubricants Meeting, 1964, pp. 561-575.

[2] D. Fiaschi, G. Manfrida, F. Maraschiello, Thermo-fluid dynamics preliminary design of turbo-expanders for ORC cycles, Applied Energy 97 (2012) 601-608. doi:10.1016/j.apenergy . 2012.02.033.

[3] S. Clemente, D. Micheli, M. Reini, R. Taccani, Bottoming organic Rankine cycle for a small scale gas turbine: A comparison of different solutions, Applied Energy 106 (2013) 355-364. doi:10.1016/j . apenergy . 2013.02 .004.

[4] E. M. Mondejar, M. Thern, M. Genrup, Aerodynamic Considerations in the Thermodynamic Analysis of Organic Rankine Cycles, in: Proceedings of the ASME 2014 Power Conference, July 28-31, 2014, pp. 1-8.

[5] J. Song, Y. Song, C.-w. Gu, Thermodynamic analysis and performance optimization of an Organic Rankine Cycle (ORC) waste heat recovery system for marine diesel engines, Energy 82 (2015) 976-985. doi:10.1016/j . energy . 2015.01.108.

[6] E. Yun, H. Park, S. Y. Yoon, K. C. Kim, Dual parallel organic Rankine cycle (ORC) system for high efficiency waste heat recovery in marine application, Journal of Mechanical Science and Technology 29 (6) (2015) 2509-2515.

[7] M.-H. Yang, R.-H. Yeh, Analyzing the optimization of an organic Rankine cycle system for recovering waste heat from a large marine engine containing a cooling water system, Energy Conversion and Management 88 (2014) 999-1010.

[8] M.-H. Yang, R.-H. Yeh, Thermodynamic and economic performances optimization of an organic rankine cycle system utilizing exhaust gas of a large marine diesel engine, Applied Energy 149 (2015) 1-12. doi:10.1016/j . apenergy . 2015.03 .083$.

[9] J. G. Andreasen, U. Larsen, F. Haglind, Design of organic Rankine cycles using a non-conventional optimization approach, Proceedings of the 28th International Conference on Efficiency, Cost, Optimization, Simulation and Environmental Impact of Energy Systems, June 30-July 3, Pau, France (2015) 1-12.

[10] A. Toffolo, A. Lazzaretto, G. Manente, M. Paci, A multi-criteria approach for the optimal selection of working fluid and design parameters in Organic Rankine Cycle systems, Applied Energy 121 (2014) 219-232. doi:10.1016/j . apenergy.2014.01.089.

[11] D. Maraver, J. Royo, V. Lemort, S. Quoilin, Systematic optimization of subcritical and transcritical organic Rankine cycles (ORCs) constrained by technical parameters in multiple applications, Applied Energy 117 (2014) 11-29. doi:10.1016/j. apenergy.2013.11.076. 
[12] J. Vivian, G. Manente, A. Lazzaretto, A general framework to select working fluid and configuration of ORCs for low-to-medium temperature heat sources, Applied Energy 156 (2015) 727-746. doi:10.1016/j.apenergy .2015.07. 005.

[13] M. Astolfi, M. C. Romano, P. Bombarda, E. Macchi, Binary ORC (Organic Rankine Cycles) power plants for the exploitation of medium-low temperature geothermal sources-Part B: Techno-economic optimization, Energy 66 (2014) 435-446.

[14] E. Martelli, F. Capra, S. Consonni, Numerical optimization of Combined Heat and Power Organic Rankine Cycles-Part A: Design optimization, Energy 90 (2015) 310-328.

[15] L. Da Lio, G. Manente, A. Lazzaretto, Predicting the optimum design of single stage axial expanders in ORC systems: Is there a single efficiency map for different working fluids?, Applied Energy 167 (2016) 44-58. doi :10.1016/j . apenergy . 2016.01.020.

[16] M. White, A. I. Sayma, Improving the economy-of-scale of small organic rankine cycle systems through appropriate working fluid selection, Applied Energy 183 (2016) 1227-1239. doi:10.1016/j . apenergy . 2016.09.055.

[17] A. Meroni, A. La Seta, J. G. Andreasen, L. Pierobon, G. Persico, F. Haglind, Combined Turbine and Cycle Optimization for Organic Rankine Cycle Power Systems-Part A: Turbine Model, Energies 9 (5) (2016) 313. doi:10.3390/ en9050313.

[18] A. La Seta, A. Meroni, J. G. Andreasen, L. Pierobon, G. Persico, F. Haglind, Combined Turbine and Cycle Optimization for Organic Rankine Cycle Power Systems_-Part B: Application on a Case Study, Energies 9 (6) (2016) 393. doi : 10.3390/en9060393.

[19] E. Macchi, M. Astolfi, Axial flow turbines for Organic Rankine Cycle applications, in: E. Macchi, M. Astolfi (Eds.), Organic Rankine Cycle (ORC) Power Systems : Technologies and Applications, Elsevier Science, 2016, Ch. 9, pp. 299-319.

[20] P. Colonna, E. Casati, C. Trapp, T. Mathijssen, J. Larjola, T. Turunen-Saaresti, A. Uusitalo, Organic Rankine Cycle Power Systems: From the Concept to Current Technology, Applications, and an Outlook to the Future, Journal of Engineering for Gas Turbines and Power 137 (10) (2015) 1-19.

[21] G. Bado, G. Tomei, T. Angelino, M. Gaia, E. Macchi, The Ansaldo 35 kW solar power system, in: Sun II - ISES Silver Jubilee Congress, May, Atlanta, Georgia, Vol. 1, 1979, pp. 1090-1094.

[22] C. Osnaghi, G. Angelino, F. Bassi, E. Bollina, P. Ferrari, M. Gaia, G. Giglioli, E. Macchi, A. Perdichizzi, Progetto e realizzazione di un motore a fluido 
organico con espansione a turbina da accoppiarsi con un impianto solare a media concentrazione, in: II Seminario Informativo dell'attivitá del sottoprogetto 'Energia Solare', Vol. 3, 1979.

[23] G. Angelino, M. Gaia, E. Macchi, Medium temperature $100 \mathrm{~kW}$ ORC engine for total energy systems, in: Energy Conservation in IndustryCombustion, Heat Recovery and Rankine Cycle Machines, Springer, 1983, pp. 177-189.

[24] A. Verneau, Supersonic turbines for organic fluid Rankine cycles from 3 to 1300 kW, Small High Pressure Ratio Turbines, (VKI Lecture Series 1987-2007) Von Karman Institute For Fluid Dynamics, Rhode-Saint-Genése, Belgium (1987) 155 .

[25] T. Jokinen, J. Larjola, I. Mikhaltsev, Power unit for research submersible, in: International Conference on Electric Ship (ElecShip 98), Istanbul, Sept, Vol. 1, 1998, pp. 114-118.

[26] L. Sciacovelli, P. Cinnella, Numerical study of multistage transcritical organic Rankine cycle axial turbines, Journal of Engineering for Gas Turbines and Power 136 (8) (2014) 082604.

[27] P. Klonowicz, J. Surwio, L. Witanowski, T. K. Suchocki, Z. Kozanecki, P. Lampart, Design and numerical study of turbines operating with MDM as working fluid, Open Engineering 5 (1) (2015) 485-499. doi:10.1515/ eng-2015-0050.

[28] J. Surwilo, P. Lampart, M. Szymaniak, CFD analysis of fluid flow in an axial multi-stage partial-admission ORC turbine, Open Engineering 5 (1) (2015) 360364. doi:10.1515/eng-2015-0042.

[29] G. Angelino, M. Gaia, E. Macchi, A. Barutti, C. Maccio, G. Tomei, Test results of a medium temperature solar engine, International Journal of Ambient Energy 3 (3) (1982) 115-126.

[30] A. Barutti, W. Pedrick, G. Angelino, M. Gaia, E. Macchi, Ansaldo Solar Thermal and Photovoltaic Plants Located at Ballajura, Western Australia, in: 8th Solar World Congress, Biennial Congress of the International Solar Energy Society,14-19 August, Perth, Australia, Vol. 3, 1983, pp. 1572-1576.

[31] G. Angelino, M. Gaia, E. Macchi, Medium Temperature 100 kW ORC Engine for Total Energy Systems - Experimental Results, Commission of the European Communities, Report EUR 9236 (1) (1984) 421.

[32] I. Obernberger, A. Hammerschmid, Biomass fired CHP plant based on an ORC cycle-Project ORC-STIA-Admont, Final Report, Bios-energy systems (2001) $1-12$.

[33] P. Nasir, S. Jones, D. Schochet, N. Sparks, Utilization of Turbine Waste Heat to Generate Electric Power at Neptune Plant, http://www.ormat.com/research/ papers/utilization-turbine-waste-heat-generate-electric-power-neptune-plant, accessed Oct. 1, 2016. 
[34] G. Lozza, E. Macchi, A. Perdichizzi, On the influence of the number of stages on the efficiency of axial-flow turbines, in: ASME 1982 International Gas Turbine Conference and Exhibit, American Society of Mechanical Engineers, 1982, pp. $1-10$.

[35] E. Macchi, A. Perdichizzi, Efficiency Prediction for Axial-Flow Turbines Operating with Nonconventional Fluids, Journal of Engineering for Power 103 (4) (1981) 718-724.

[36] M. Pini, G. Persico, E. Casati, V. Dossena, Preliminary Design of a Centrifugal Turbine for Organic Rankine Cycle Applications, Journal of Engineering for Gas Turbines and Power 135 (4) (2013) 042312. doi : 10.1115/1.4023122.

[37] E. Casati, S. Vitale, M. Pini, G. Persico, P. Colonna, Centrifugal Turbines for Mini-ORC Power Systems, Journal of Engineering for Gas Turbines and Power 136 (December 2014) (2014) 1-11. doi:10 .1115/1 . 4027904.

[38] G. Persico, M. Pini, Fluid dynamic design of Organic Rankine Cycle turbines, in: E. Macchi, M. Astolfi (Eds.), Organic Rankine Cycle (ORC) Power Systems : Technologies and Applications, Elsevier Science, 2016, Ch. 8, pp. 253-297.

[39] E. Casati, S. Vitale, M. Pini, G. Persico, P. Colonna, Preliminary Design Method For Small Scale Centrifugal ORC Turbines, http://www.asme-orc2013. nl/uploads/File/PPT\%20155.pdf, Accessed Aug. 15, 2017 (2013).

[40] MAN Diesel \& Turbo, Waste Heat Recovery System (WHRS) - Marine Engines \& Systems, http://marine.man.eu/ (Aug. 2015).

[41] J. G. Andreasen, A. Meroni, F. Haglind, A Comparison of Organic and Steam Rankine Cycle Power Systems for Waste Heat Recovery on Large Ships, Energies 10 (4) (2017) 547 (23 pp.), 547 (23 pp.). doi : 10.3390/en10040547.

[42] U. Larsen, L. Pierobon, F. Haglind, C. Gabrielii, Design and optimisation of organic Rankine cycles for waste heat recovery in marine applications using the principles of natural selection, Energy 55 (45) (2013) 803-812. doi : 10.1016/ j.energy. 2013.03.021.

[43] S. Quoilin, M. V. D. Broek, S. Declaye, P. Dewallef, V. Lemort, Technoeconomic survey of Organic Rankine Cycle (ORC) systems, Renewable and Sustainable Energy Reviews 22 (2013) 168-186. doi:10.1016/j.rser. 2013.01 .028$.

[44] J. Bao, L. Zhao, A review of working fluid and expander selections for organic Rankine cycle, Renewable and Sustainable Energy Reviews 24 (2013) 325-342. doi:10.1016/j.rser.2013.03.040.

[45] D. Wang, X. Ling, H. Peng, L. Liu, L. Tao, Efficiency and optimal performance evaluation of organic Rankine cycle for low grade waste heat power generation, Energy 50 (1) (2013) 343-352. doi:10.1016/j . energy . 2012 .11.010. 
[46] H. Öhman, P. Lundqvist, Screw expanders in orc applications, review and a new perspective, in: 3rd International Seminar on ORC Power Systems, October 1214, Brussels, Belgium, 2015, pp. 1-10.

[47] Ozone Secretariat UNEP, Montreal Protocol on Substances that Deplete the Ozone Layer, US Government Printing Office, 1987., Tech. rep.

[48] Official Journal of the European Union, Regulation (EU) no 517/2014 of the European parliament and of the council on fluorinated greenhouse gases and repealing regulation (EC) no 842/2006, Tech. rep.

[49] R. Rayegan, Y. Tao, A procedure to select working fluids for Solar Organic Rankine Cycles (ORCs), Renewable Energy 36 (2) (2011) 659-670.

[50] U. Drescher, D. Brüggemann, Fluid selection for the Organic Rankine Cycle (ORC) in biomass power and heat plants, Applied thermal engineering 27 (1) (2007) 223-228.

[51] W. C. Andersen, T. J. Bruno, Rapid screening of fluids for chemical stability in organic Rankine cycle applications, Industrial \& Engineering Chemistry Research 44 (15) (2005) 5560-5566.

[52] Green Energy You Can Rely On, www.ormat.com, Accessed Oct. 1, 2016.

[53] EG, EGi, EEGi-Series Atlas Copco Gas and Process, http://www. atlascopco-gap.com/products/expanders/eg-egi-eegi-series, Accessed Oct. 1, 2016.

[54] M. Preißinger, D. Brüggemann, Thermal stability of hexamethyldisiloxane (MM) for high-temperature organic Rankine cycle (ORC), Energies 9 (3) (2016) 183.

[55] D. E. Williams, Volatile Methyl Siloxanes: Environmentally Sound Solvent Systems, ACS Publications, 2000.

[56] Turboden: Clean Energy Ahead, www.turboden.eu, Accessed Oct. 1, 2016.

[57] E. Macchi, Theoretical basis of the Organic Rankine cycle, in: E. Macchi, M. Astolfi (Eds.), Organic Rankine Cycle (ORC) Power Systems : Technologies and Applications, Elsevier Science, 2016, Ch. 1, pp. 3-24.

[58] M. Pasetti, C. M. Invernizzi, P. Iora, Thermal stability of working fluids for organic Rankine cycles: An improved survey method and experimental results for cyclopentane, isopentane and n-butane, Applied Thermal Engineering 73 (1) (2014) 764-774.

[59] D. M. Ginosar, L. M. Petkovic, D. P. Guillen, Thermal stability of cyclopentane as an organic Rankine cycle working fluid, Energy \& Fuels 25 (9) (2011) 41384144 .

[60] Ge oil \& gas - ORegen, http://www.geoilandgas.com, Accessed Oct. 1, 2016. 
[61] Aqylon - Smarter Power, http://www.aqylon.com/products-range/, Accessed Oct. 1, 2016.

[62] W. Collins, R. Derwent, C. Johnson, D. Stevenson, The oxidation of organic compounds in the troposphere and their global warming potentials, Climatic Change 52 (4) (2002) 453-479.

[63] G. C. Straty, M. Ball, T. Bruno, PVT of toluene at temperatures to 673 K, Journal of Chemical and Engineering Data 33 (2) (1988) 115-117.

[64] Triogen - Power From Heat, http://www.triogen.nl/, Accessed Oct. 1, 2016.

[65] G. Angelino, C. Invernizzi, Experimental investigation on the thermal stability of some new zero ODP refrigerants, International Journal of Refrigeration 26 (1) (2003) 51-58.

[66] Calnetix - Organic Rankine Cycle Systems, http://www.calnetix.com/ organic-rankine-cycle-systems, Accessed Oct. 1, 2016.

[67] Cryostar- Clean Energy, http://www.cryostar.com/web/power-electricity, Accessed Oct. 1, 2016.

[68] E-Rational - Value for Heat, http://www.e-rational.net/, Accessed Oct. 1, 2016.

[69] H. Craig, H. Cox, Performance estimation of axial flow turbines, Proceedings of the Institution of Mechanical Engineers 185 (1) (1970) 407-424.

[70] P. Klonowicz, F. Heberle, M. Preißinger, D. Brüggemann, Significance of loss correlations in performance prediction of small scale, highly loaded turbine stages working in Organic Rankine Cycles, Energy 72 (2014) 322-330. doi:10.1016/j.energy. 2014.05.040.

[71] E. Macchi, Design criteria for turbines operating with fluids having a low speed of sound, Closed Cycle Gas Turbines. (VKI Lecture Series 100) Von Karman Institute For Fluid Dynamics, Rhode-Saint-Genése, Belgium 2 (1977) 1-34.

[72] J. Dunham, P. Came, Improvements to the Ainley-Mathieson method of turbine performance prediction, Journal of Engineering for Power 92 (3) (1970) 252256.

[73] C. Invernizzi, P. Iora, P. Silva, Bottoming micro-Rankine cycles for micro-gas turbines, Applied thermal engineering 27 (1) (2007) 100-110.

[74] G. Angelino, C. Invernizzi, Cyclic methylsiloxanes as working fluids for space power cycles, Journal of solar energy engineering 115 (3) (1993) 130-137.

[75] G. Angelino, C. Invernizzi, G. Molteni, The potential role of organic bottoming Rankine cycles in steam power stations, Proceedings of the Institution of Mechanical Engineers, Part A: Journal of Power and Energy 213 (2) (1999) 75-81. 
[76] C. Maccio, G. Tomei, G. Angelino, M. Gaia, E. Macchi, Operational experience of a $3.0 \mathrm{~kW}$ solar powered water pump, in: Sun II, Vol. 1, 1979, pp. 1501-1505.

[77] P. Kötzing, B. Evers, Test case e/tu, 4-stage low speed turbine. AGARD Advisory Report N.275, Tech. rep., AGARD.

[78] C. Hirsch, J. Denton, Through Flow Calculations in Axial Turbomachines. AGARD Advisory Report N.175, Tech. rep., AGARD. Propulsion and Energetics Panel. Working Group 12 (1981).

[79] N. Herzog, M. Binner, J. Seume, K. Rothe, Verification of low-flow conditions in a multistage turbine, in: ASME Turbo Expo 2007: Power for Land, Sea, and Air, American Society of Mechanical Engineers, 2007, pp. 563-574.

[80] G. Gerolymos, C. Hanisch, Multistage three-dimensional navier-stokes computation of off-design operation of a four-stage turbine, Proceedings of the Institution of Mechanical Engineers, Part A: Journal of Power and Energy 213 (4) (1999) 243-261.

[81] G. Croce, L. Ratto, A. Satta, A navier stokes solver for axisymmetric turbomachinery analysis, in: 5th European conference on Computational Fluid Dynamics, 14-17 June, Lisbon, Portugal, 2010, pp. 1-12.

[82] C. Cravero, P. Macelloni, G. Briasco, Three-Dimensional Design Optimization of Multistage Axial Flow Turbines Using a RSM Based Approach, in: ASME Turbo Expo 2012: Turbine Technical Conference and Exposition, June 11-15, Copenhagen, Denmark, American Society of Mechanical Engineers, 2012, pp. 1873-1884.

[83] G. Gerolymos, I. Vallet, Tip-clearance and secondary flows in a transonic compressor rotor, in: ASME 1998 International Gas Turbine and Aeroengine Congress and Exhibition, American Society of Mechanical Engineers, 1998, pp. V001T01A093-V001T01A093.

[84] G. Gerolymos, Implicit multiple-grid solution of the compressible NavierStokes equations using k-epsilon turbulence closure, AIAA journal 28 (10) (1990) 1707-1717.

[85] A. Verneau, Waste Heat Recovery by Organic Fluid Rankine Cycle, in: Proceedings from the First Industrial Energy Technology Conference, April 22-25, Houston, TX, 1979, pp. 940-952.

[86] E. W. Lemmon, M. L. Huber, M. O. McLinden, NIST reference fluid thermodynamic and transport properties-REFPROP (2013).

[87] J. Boy-Marcotte, 100-1000 kW (el) medium-power distributed-collector solar system, Electric Power Systems Research 3 (1) (1980) 41-51.

[88] A. Kluwick, Nonlinear waves in real fluids, Springer, 1991. 
[89] K. G. Joback, R. C. Reid, Estimation of pure-component properties from groupcontributions, Chemical Engineering Communications 57 (1-6) (1987) 233-243.

[90] N. Metropolis, S. Ulam, The Monte Carlo Method, Journal of the American Statistical Association 44 (247) (1949) 335-341. doi:10.1080/01621459. 1949.10483310.

[91] C. Osnaghi, Teoria delle turbomacchine, Società Editrice Esculapio, 2013.

[92] G. Sin, K. V. Gernaey, A. E. Lantz, Good Modeling Practice for PAT Applications: Propagation of Input Uncertainty and Sensitivity Analysis, Biotechnology Progress 25 (4) (2009) 1043-1053.

[93] S. Lecompte, H. Huisseune, M. van den Broek, S. De Schampheleire, M. De Paepe, Part load based thermo-economic optimization of the Organic Rankine Cycle (ORC) applied to a combined heat and power (CHP) system, Applied Energy 111 (2013) 871-881.

[94] S. Lemmens, A perspective on costs and cost estimation techniques for organic Rankine cycle systems, in: Proceedings of the 3rd International Seminar on ORC Power Systems (ASME ORC 2015), Brussels, Belgium, 2015, pp. 12-14.

[95] S. Quoilin, S. Declaye, B. F. Tchanche, V. Lemort, Thermo-economic optimization of waste heat recovery Organic Rankine Cycles, Applied thermal engineering 31 (14) (2011) 2885-2893.

[96] S. Lecompte, S. Lemmens, H. Huisseune, M. van den Broek, M. De Paepe, Multi-objective thermo-economic optimization strategy for ORCs applied to subcritical and transcritical cycles for waste heat recovery, Energies 8 (4) (2015) 2714-2741.

[97] T. Tartière, B. Obert, L. Sanchez, Thermo-economic optimization of subcritical and transcritical ORC systems, in: ASME ORC 2013-International seminar on ORC power systems, 2013, pp. 1-12.

[98] L. Bronicki, Experience with high speed organic Rankine cycle turbomachinery, in: Conference on High Speed Technology, Lappeenranta University of Technology, August, Lappeenrata, Finland, 1988, pp. 21-24.

[99] M. Pini, G. Persico, D. Pasquale, S. Rebay, Adjoint method for shape optimization in real-gas flow applications, Journal of Engineering for Gas Turbines and Power 137 (3) (2015) 032604.

[100] P. Rodriguez-Fernandez, G. Persico, Automatic design of ORC turbine profiles using evolutionary algorithms, in: Proceedings of the Third International Seminar on ORC Power Systems, October 12-14, Brussels, Belgium, 2015, pp. 1-10.

[101] G. Horn, T. Norris, J. Whybrow, Turbine Flow Problems of Binary Cycles Employing High Density Fluids, Proceedings of the Institution of Mechanical Engineers 183 (1) (1968) 165-178. 
[102] J. Tollefson, Nations agree to ban refrigerants that worsen climate change, http: //www.nature.com, Accessed Feb. 1, 2017. 